University of Nebraska - Lincoln

DigitalCommons@University of Nebraska - Lincoln

2006

Incorporating Animal Behavior Into Seed Dispersal Models: Implications For Seed Shadows

\author{
Sabrina E. Russo \\ University of Nebraska - Lincoln, srusso2@unl.edu \\ Stephen Portnoy \\ University of Illinois at Urbana-Champaign, sportnoy@illinois.edu \\ Carol K. Augspurger \\ University of Illinois at Urbana-Champaign, carolaug@life.uiuc.edu
}

Follow this and additional works at: https://digitalcommons.unl.edu/bioscifacpub

Russo, Sabrina E.; Portnoy, Stephen; and Augspurger, Carol K., "Incorporating Animal Behavior Into Seed Dispersal Models: Implications For Seed Shadows" (2006). Faculty Publications in the Biological Sciences. 257.

https://digitalcommons.unl.edu/bioscifacpub/257

This Article is brought to you for free and open access by the Papers in the Biological Sciences at DigitalCommons@University of Nebraska - Lincoln. It has been accepted for inclusion in Faculty Publications in the Biological Sciences by an authorized administrator of DigitalCommons@University of Nebraska - Lincoln. 


\title{
INCORPORATING ANIMAL BEHAVIOR INTO SEED DISPERSAL MODELS: IMPLICATIONS FOR SEED SHADOWS
}

\author{
Sabrina E. Russo, ${ }^{1,4}$ Stephen Portnoy, ${ }^{2}$ and Carol K. Augspurger ${ }^{3}$ \\ ${ }^{1}$ Department of Animal Biology, University of Illinois, 515 Morrill Hall, 505 South Goodwin Avenue, Urbana, Illinois 61801 USA \\ ${ }^{2}$ Department of Statistics, University of Illinois, 101 Illini Hall, 725 South Wright Street, Champaign, Illinois 61820 USA \\ ${ }^{3}$ Department of Plant Biology, University of Illinois, 265 Morrill Hall, 505 South Goodwin Avenue, Urbana, Illinois 61801 USA
}

\begin{abstract}
Seed dispersal fundamentally influences plant population and community dynamics but is difficult to quantify directly. Consequently, models are frequently used to describe the seed shadow (the seed deposition pattern of a plant population). For vertebratedispersed plants, animal behavior is known to influence seed shadows but is poorly integrated in seed dispersal models. Here, we illustrate a modeling approach that incorporates animal behavior and develop a stochastic, spatially explicit simulation model that predicts the seed shadow for a primate-dispersed tree species (Virola calophylla, Myristicaceae) at the forest stand scale. The model was parameterized from field-collected data on fruit production and seed dispersal, behaviors and movement patterns of the key disperser, the spider monkey (Ateles paniscus), densities of dispersed and non-dispersed seeds, and direct estimates of seed dispersal distances. Our model demonstrated that the spatial scale of dispersal for this $V$. calophylla population was large, as spider monkeys routinely dispersed seeds $\gg 100 \mathrm{~m}$, a commonly used threshold for long-distance dispersal. The simulated seed shadow was heterogeneous, with high spatial variance in seed density resulting largely from behaviors and movement patterns of spider monkeys that aggregated seeds (dispersal at their sleeping sites) and that scattered seeds (dispersal during diurnal foraging and resting). The single-distribution dispersal kernels frequently used to model dispersal substantially underestimated this variance and poorly fit the simulated seed-dispersal curve, primarily because of its multimodality, and a mixture distribution always fit the simulated dispersal curve better. Both seed shadow heterogeneity and dispersal curve multimodality arose directly from these different dispersal processes generated by spider monkeys. Compared to models that did not account for disperser behavior, our modeling approach improved prediction of the seed shadow of this $V$. calophylla population. An important function of seed dispersal models is to use the seed shadows they predict to estimate components of plant demography, particularly seedling population dynamics and distributions. Our model demonstrated that improved seed shadow prediction for animal-dispersed plants can be accomplished by incorporating spatially explicit information on disperser behavior and movements, using scales large enough to capture routine long-distance dispersal, and using dispersal kernels, such as mixture distributions, that account for spatially aggregated dispersal.
\end{abstract}

Key words: Ateles paniscus; dispersal kernel; mechanistic model; mixture distribution; Myristicaceae; seed dispersal; seed shadow; spider monkey; Virola calophylla.

\section{INTRODUCTION}

Seed dispersal fundamentally influences a plant population's spatial structure and dynamics because it establishes the initial spatial template of offspring dispersion. Quantifying the seed shadow, the spatial distribution of seeds, has long been a goal of plant biologists because it potentially has vast consequences for plant ecological and evolutionary processes. From an ecological perspective, the spatial pattern of seed deposition mediates the probability of successful transition from the seed to the seedling stage through its effects

Manuscript received 4 January 2006; revised 8 May 2006; accepted 5 June 2006. Corresponding Editor: M. Wikelski.

${ }^{4}$ Present address: Department of Plant Sciences, University of Cambridge, Downing Street, Cambridge CB2 3EA UK. E-mail: ser48@cam.ac.uk on post-dispersal processes such as density-dependent seed survival and colonization of new habitats (Howe and Miriti 2004). Over evolutionary time, seed deposition patterns determine both gene flow between populations and the frequency with which a species experiences new selection regimes, which facilitate evolution in novel environments (Slatkin 1985, Herrera 2002, Holt et al. 2004). Seed dispersal also may have community-level consequences (Levine and Murrell 2003). In theoretical models, seed deposition patterns can shape species accumulation curves and abundance distributions and affect species coexistence (Levin 1974, Hurtt and Pacala 1995, Hubbell 2001, Chave et al. 2002). Because the seed shadow potentially influences so many processes shaping plant population and community structure and evolution, it is important to be able to quantify the spatial distributions of seeds accurately. 
This importance notwithstanding, seed dispersal in nature is notoriously difficult to quantify directly for plant species, especially forest trees. As a result, models of seed dispersal, in particular inverse and mechanistic models, have played a prominent role in predicting the spatial distributions of seeds (Nathan and MullerLandau 2000). The inverse-modeling approach estimates parameter values for dispersal functions that result in the best fit to seed-deposition data from seed traps, given a model of dispersal describing the probability distributions of distances traveled by seeds from mapped individual source trees (known as the seed dispersal kernel or dispersal curve) (Ribbens et al. 1994, Clark et al. 1999). One limitation of inverse modeling is that the resulting seed shadow depends upon the dispersal kernels used, and it is unclear whether commonly used dispersal kernels involving single probability distributions (e.g., the lognormal distribution) adequately represent seed shadows generated by dispersal agents in nature (Clark et al. 1999, Jones et al. 2005). This is particularly true for vertebrate dispersers, which often generate spatially aggregated seed-deposition patterns (Schupp et al. 2002). In addition, vertebrates often have large home ranges (Mack 1995, Holbrook et al. 2002, Chapman and Russo 2006), making estimation of routine, longer-distance dispersal difficult.

Alternatively, mechanistic models predict seed dispersal directly from the traits of plants and their dispersal agents. Seed dispersal by wind has been particularly amenable to mechanistic modeling (Greene and Johnson 1989, Bullock and Clarke 2000, Nathan et al. 2001), as the properties that influence seed transport, such as wind speed, wing loading, and height of release, are identifiable from aerodynamics and are measurable. To date, mechanistic models of animal dispersal have posed a greater challenge primarily because animal movement patterns are complex and can be difficult to quantify. They depend on many factors, including the distribution of food and other resources, (e.g., nesting or lekking sites), animal responses to those resources, individual disposition (e.g., age, sex, and dominance rank), and social system (Symington 1987, Chapman et al. 1989, Norconk and Kinzey 1994, Boinski and Garber 2000, Westcott and Graham 2000).

Mechanistic models of dispersal by animals have focused on predicting seed-dispersal curves based on seed passage times and displacement rates of animals (Murray 1988, Wehncke et al. 2003, Westcott et al. 2005). Such models have not incorporated spatially explicit data on the directionality of movements in such a way that allows prediction of the spatial pattern of seed deposition. Hence, existing mechanistic models may underestimate clumping of animal-dispersed seeds (Muller-Landau and Hardesty 2005), although such clumping should be reflected in multimodality of the predicted seed-dispersal curve (Wescott et al. 2005).

An important function of seed dispersal models is to estimate components of plant demography, particularly the transition from seed to later life stages, in order to predict spatial patterns of recruitment (Nathan et al. 2000, Fragoso et al. 2003, Howe and Miriti 2004). If seed dispersal models do not accurately reproduce clumping of seed deposition (i.e., they underestimate the spatial variance in seed density), then biased estimates of seedling population dynamics will result (Chesson et al. 2005). The prediction of the seed distribution patterns generated by animals can be improved by parameterizing mechanistic models based on the behavior and movement patterns of animal dispersers. Better prediction of seed distribution patterns is fundamental to understanding not only the broader implications of seed dispersal for plant populations and communities, but also the impacts of modified seed dispersal patterns associated with anthropogenic change, such as the extirpation of vertebrates from forests (Wright et al. 2000), the effects of climate change on fecundity (LaDeau and Clark 2001), and the spread of introduced plants (Renne et al. 2002).

We set out to address the need for more detailed models of seed dispersal by animals by developing a spatially explicit, mechanistic model of seed dispersal by the spider monkey (Ateles paniscus) and using it to simulate the seed shadow for a Neotropical tree species, Virola calophylla (Myristicaceae), at the scale of a forest stand in mature floodplain forest in Amazonian Peru. Primates disperse a majority of seeds in many tropical forests (McConkey 2000, Chapman and Russo 2006). They therefore may have a disproportionate influence on tropical forest tree population and community dynamics, making it vitally important to predict their influence on seed-deposition patterns. This is a particularly urgent need, given rising rates of defaunation in tropical forests (Peres 2000).

Our simulation model is based on fruit production and seed dispersal in one year from a stand of $V$. calophylla trees. We empirically estimated probability distributions, integrating the salient features of the behaviors and movement patterns of spider monkeys that affect how they disperse seeds, including densities of dispersed and non-dispersed seeds, and direct estimates of seed dispersal distances. These quantitative natural history data were the core of our stochastic model simulating seed dispersal by spider monkeys. Here, we first illustrate the development of this model. Second, we use the output from the model to (1) describe the seed shadow of this $V$. calophylla population at the forest stand scale, (2) describe the individual- and populationlevel seed-dispersal curves of $V$. calophylla, and (3) test whether these curves are well-fit by the single-distribution dispersal kernels commonly used to model seed dispersal.

\section{Study site and species}

This study was conducted from August 1999 through December 2001 at Cocha Cashu Biological Station (CCBS) in Manú National Park, Perú (18812 km², 


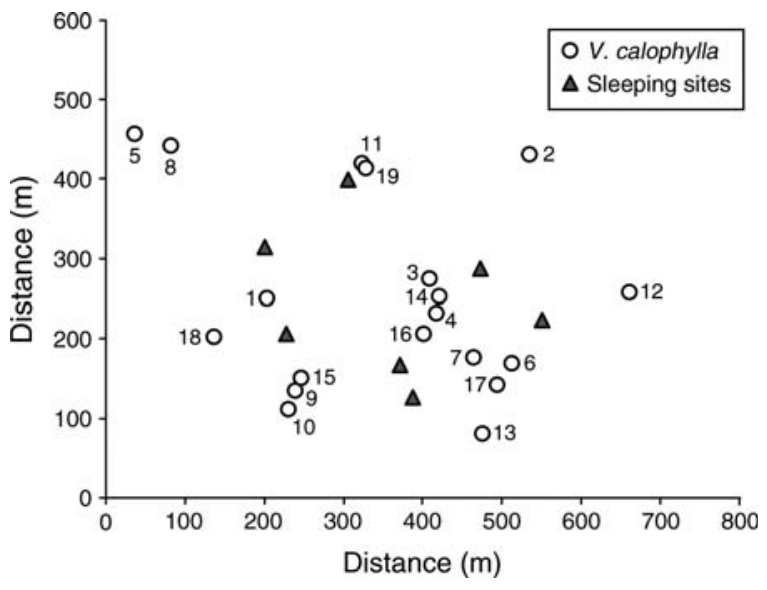

FIG. 1. Map of study plot with locations of the 19 Virola calophylla trees producing fruit in 2001 (circles) and seven reused sleeping sites (triangles). Numbered circles correspond to numbered source trees in Appendix A.

$11^{\circ} 54^{\prime} \mathrm{S}, 71^{\circ} 18^{\prime} \mathrm{W}$, elevation $\left.\sim 400 \mathrm{~m}\right)$. The average annual rainfall is $\sim 2000 \mathrm{~mm}$, with most precipitation falling between October and April (Terborgh 1983). CCBS consists of a mosaic of forest types ranging from the earliest successional stage on point bars of the Manú River to mature floodplain forest. This site has been described in detail in previous publications (Terborgh 1983).

Dispersal system.-Species of Virola have been a model system for studying seed dispersal (e.g., Howe et al. 1985, Forget and Milleron 1991). Virola calophylla is a dioecious, shade-tolerant, canopy tree of South American lowland moist forests (Rodrigues 1980). At CCBS, V. calophylla was found to occur at an average density of 2.9 trees $\geq 10 \mathrm{~cm}$ diameter per hectare and to be spatially aggregated relative to a pattern of complete spatial randomness at spatial scales of 30-231 m (Russo and Augspurger 2004), as estimated using the Ripley's $K$ statistic (Ripley 2003). From early to mid-September through December at CCBS, $V$. calophylla ripens its fruit, which is a bivalved, green capsule that opens upon ripening to expose a single seed with a bright red, oily aril. Most of the volume of the diaspore consists of the seed (length $17.0 \pm 1.8 \mathrm{~mm}, n=98$; fresh mass, $1.4 \pm 0.5$ g, $n=108$; values are mean $\pm \mathrm{SD}$ ).

At CCBS, $V$. calophylla seeds are dispersed by at least 17 bird species and one primate species, the spider monkey, Ateles paniscus. Spider monkey population density at CCBS in 1976-1977 was 25 individuals $/ \mathrm{km}^{2}$ (Terborgh 1983). The ranges of two spider monkey communities are completely contained within the CCBS trail system, and few mature or late successional forest areas within the trail system are outside of the range of any spider monkey community (Symington 1987). The $\sim 300$ ha of mature floodplain forest used in this study roughly coincide with the range of the spider monkey community east of the lake at CCBS, making the study area representative of the dispersal services received by $V$. calophylla from spider monkeys at this site.

Based on two years' observations at fruiting $V$. calophylla trees, spider monkeys dispersed $92 \%$ of all dispersed seeds (Russo 2003). This result is consistent with several studies, indicating that spider monkeys are important dispersers of Virola species throughout the Neotropics (Russo et al. 2005). Spider monkeys ingested up to 104 seeds in a visit and defecated them intact after gut passage times ranging from $\sim 2.5$ to $18 \mathrm{~h}$ (Milton 1981; S. E. Russo, unpublished data). They are highly frugivorous, have diverse fruit diets, forage primarily in the canopy and subcanopy, and have large home ranges (150-230 ha, Symington 1987). Secondary dispersal of $V$. calophylla by rodents (Russo 2005) or dung beetles (Andresen 1994) appears to be limited at CCBS. Thus, the majority of variation in the spatial pattern of seed dispersal of this tree is described by the patterns generated by $A$. paniscus.

\section{Model development}

We developed an individual-based, spatially explicit, mechanistic model simulating seed dispersal by the spider monkey. This model (written in the $\mathrm{S}$ language (Becker and Chambers 1984)) predicts the spatial pattern of seed deposition produced by a stand of $V$. calophylla trees by simulating the locations of individual dispersed and non-dispersed seeds (those falling below the parent crown) for all seeds originating from source trees within the stand. The model is parameterized based on field-collected data describing the important features of dispersal by spider monkeys, which were identified through field observations and are detailed in the following section.

Field data.-A study plot $(38.7$ ha; $530 \times 730 \mathrm{~m})$ was established approximately in the center of the range of the spider monkey community on the east side of the oxbow lake at CCBS (Symington 1987), and all $V$. calophylla trees $>10 \mathrm{~cm}$ diameter at breast height (dbh) within it were mapped. In 2001, 19 of these trees produced fruit (Fig. 1), which comprised $66 \%$ of all female trees (a tree was classified as female if it produced fruit at least once during 1999-2001). For each of the 19 trees, the numbers of dispersed and non-dispersed seeds were estimated (Appendix A). For 12 trees, fruit traps were used for this estimation (according to Russo [2003]). For the seven trees without fruit traps, visual estimates of crop size were made by counting the number of fruits. Visual and trap-based estimates were correlated (Pearson $r=0.93, P<0.0001, N=18$; S. E. Russo, unpublished data). The percentage of seeds dispersed for these seven trees was then assigned by randomly selecting it from a log-spline-smoothed empirical distribution (see Model structure) of the percentage of the seed crop dispersed based on fruit trap data for a sample of 32 trees producing fruit in 1999-2001 (S. E. Russo, unpublished data). For these 
seven trees, the numbers of dispersed and non-dispersed seeds were then derived from these quantities.

Individual spider monkeys that fed in $V$. calophylla were followed to describe movements and behaviors influencing seed dispersal patterns and to estimate dispersal distances and densities of seeds dispersed by spider monkeys. Focal individuals, generally members of foraging parties consisting of multiple monkeys, were chosen for study in three ways: (1) by following them as they left their sleeping sites in the morning, (2) by finding them in the early morning (dawn to $~ 09: 00$ ) feeding at fruiting $V$. calophylla trees, or (3) by finding them in the late afternoon ( 14:00 to dusk) feeding at fruiting $V$. calophylla trees. The first two methods were used to estimate dispersal to in-transit and sleeping sites. The third was only used to estimate dispersal to sleeping sites, unless the focal individual from the previous day was located at its sleeping site and then followed the next morning. Sleeping sites were located by following a focal individual until $\mathrm{s} /$ he settled into a particular tree at nightfall and then waiting for $\sim 30$ minutes after complete darkness to ensure that the individual did not move. Focal individuals were followed for as long as possible, wherever they went. Observation periods (defined as the entire time a single focal individual was observed) lasted 5-20 h (including overnight periods) and were not limited to the tree plot. When the focal individual was lost or $V$. calophylla seeds were no longer defecated, that observation was terminated.

Spider monkeys dispersed seeds to two types of sites. First, spider monkeys defecated seeds during diurnal resting or foraging. During morning and early afternoon foraging, spider monkeys moved rapidly from one fruiting tree to the next. Seeds ingested early tended to be defecated later that same day in-transit during foraging or resting, often very far from the parent tree. This dispersal site type will be referred to as an "intransit site." Second, spider monkeys tended to move more slowly later in the day, and seeds ingested in late afternoon were usually defecated the following morning at their sleeping sites. This dispersal site type will be referred to as a "sleeping site." These movement and defecation patterns are consistent with other investigations of spider monkeys, as well as of other ateline monkey species (Chapman et al. 1989, Stevenson 2000, Dew 2001).

In order to parameterize the simulation model, the spatial pattern of seed deposition was quantified at smaller spatial scales by measuring the areas of and seed densities at dispersal site types. The areas of in-transit and sleeping sites $(N=14$ sites each) and the densities of dispersed (freshly defecated) $V$. calophylla seeds were estimated within $0.25-\mathrm{m}^{2}$ quadrats in each site $(N=90$ quadrats at in-transit sites; $N=201$ quadrats at sleeping sites) using the methods in Russo and Augspurger (2004). In-transit sites were consistent with a pattern of scatter dispersal (sensu Howe [1989]: one to a few seeds dispersed at a site) based on their smaller area and lower density of $V$. calophylla seeds, relative to sleeping sites and under $V$. calophylla crowns (Russo and Augspurger 2004). In-transit sites were infrequently reused, and only a few individual monkeys at a time defecated seeds there. As a result, seeds dispersed in-transit tended to be distributed at widely spaced locations in the forest. In contrast, seed dispersal to sleeping sites had a clumped pattern (sensu Howe [1989]: defecation of multiple seeds in masses) because sleeping sites were large in area and accumulated high densities of seeds, relative to in-transit sites (Russo and Augspurger 2004). Based on weekly observations at 12 sleeping sites, $67 \%$ of sleeping sites were reused at least once over four months, and several were reused over three years (Fig. 1), with the frequency of reuse varying among individual sleeping sites. Many monkeys often congregated at reused sleeping sites, contributing to the large numbers of seeds defecated there. These observations are consistent with a study of spider monkeys in Costa Rica (Ateles geoffroyi), which reused $82 \%$ of their sleeping sites (Chapman et al. 1989).

Dispersal distances of seeds dispersed by spider monkeys to in-transit and sleeping sites were estimated directly by following individual monkeys that had fed in $V$. calophylla trees until the $V$. calophylla seeds were defecated (using the focal individual methods). In any study of seed dispersal, the possibility of incorrectly assigning seeds to parents exists. We used the following procedures (as in Stevenson 2000) in the field to minimize this possibility. (1) The observation of the focal individual was continuous or nearly so from the times of ingestion to defecation of $V$. calophylla seeds. (2) $V$. calophylla seeds were attributed to the parent if they were defecated at least $3.5 \mathrm{~h}$ after ingestion, which is the modal passage time for seeds defecated diurnally in wild spider monkeys (Dew 2001). This condition made it unlikely that $V$. calophylla seeds had already been present in the gut at the beginning of the observation. (3) Estimates of dispersal distances emphasized the beginning of the fruiting period of the $V$. calophylla population, when there were fewer trees fruiting simultaneously. This is unlikely to have affected dispersal distance estimates because spider monkeys never exclusively feed on $V$. calophylla, but have diverse fruit diets. (4) Because fruiting $V$. calophylla were spatially and temporally aggregated, monkeys frequently visited several trees in a clump in rapid succession (in approximately $<20$-min time periods). In such cases, seeds from two or more individuals became mixed in the digestive tract and could not be unambiguously assigned to a single parent tree. Therefore, if multiple seeds were defecated, then each parent was assumed to have contributed at least one seed to the defecation. Because trees in clumps were generally $<30 \mathrm{~m}$ from each other, this is unlikely to have appreciably affected dispersal distances estimates. The empirical distribution of dispersal distances (Fig. 2) was estimated as the frequency of distances to which at least one seed from 

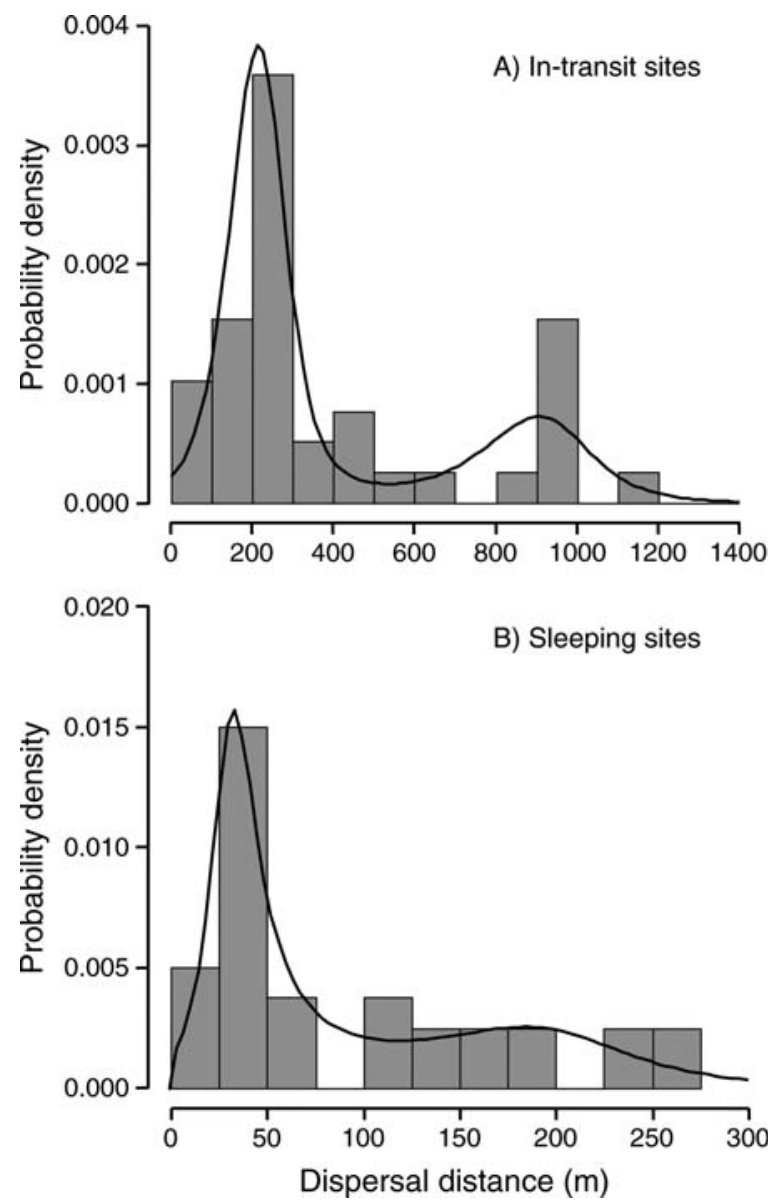

FIG. 2. Probability distributions of seed dispersal distances to $(\mathrm{A})$ in-transit sites $(N=39)$ and $(\mathrm{B})$ sleeping $(N=32)$ sites. Shown are the number of distances to which at least one seed in a spider monkey defecation was dispersed from a source tree. The observed distance distributions are shown with gray bars, and densities modeled using log-spline density estimation are shown with curves.

a given parent was dispersed for in-transit $(N=39)$ and sleeping $(N=32)$ sites.

The total number of dispersed seeds for each source tree was estimated by subtracting the number of nondispersed seeds from the crop size. We assumed that $92 \%$ of dispersed seeds were dispersed by spider monkeys, as has been observed at fruiting $V$. calophylla trees (Russo 2003). This percentage was applied to all trees independently of crop size because neither the visitation rate nor the number of seeds dispersed by spider monkeys per visit at $V$. calophylla trees was significantly affected by crop size (Russo 2003). Of these spider monkey dispersed seeds, half were assumed to be dispersed intransit and half dispersed at sleeping sites. This simplifying assumption was based on field observations indicating that although an individual monkey may make more in-transit than sleeping site defecations per day, sleeping site defecations have higher seed density, thereby balancing out the contribution of seeds to the two dispersal site types. Direct quantification of the total numbers of seeds dispersed in transit and at sleeping sites was not possible because of difficulty finding every seed that was ingested in a foraging bout (a maximum of 104 seeds).

Model structure.-The dominant processes observed to affect seed dispersal in $V$. calophylla represent the model's four main subroutines (flow diagram in Appendix B), as described in the following sections: (1) seeds falling below the parent tree (non-dispersed seeds), seeds dispersed by spider monkeys to (2) in-transit sites, (3) single-use sleeping sites, and (4) reused sleeping sites. All seeds originated from the 19 trees bearing fruit in 2001 in the study plot (Appendix A), and the area of forest receiving seeds was determined by the simulation itself.

Dispersal processes were simulated stochastically by randomly sampling from statistical distributions fit to empirical data. Parameters were estimated using maximum likelihood or other estimators (Hilborn and Mangel 1997) and classical goodness-of-fit tests, such as the chi-square, Komolgorov-Smirnov, and Cramervon Mises tests (Sokal and Rohlf 1995). When no single distribution could be fit to a set of continuous empirical data, then the probability density was estimated using log-spline density estimation, which is a nonparametric, empirical density estimation method that is applicable to data arising as a random sample from a distribution having an unknown but smooth probability density (Kooperberg and Stone 1991).

Non-dispersed seeds.-Non-dispersed seeds were distributed in groups by first randomly selecting a location under each parent crown to receive seeds. Then, the number of seeds in each group was selected by randomly sampling from the empirical distribution of the number of seeds per $0.25 \mathrm{~m}^{2}$ below the crown, as estimated based on seedfall into fruit traps underneath fruiting $V$. calophylla trees $(N=12$ trees).

Seeds dispersed in-transit. - For each tree, seeds were dispersed in-transit by simulating individual defecations iteratively. The number of seeds in each defecation was selected from the distribution of seed densities at intransit sites (Fig. 3A). A one-parameter geometric distribution was fit to these data using the maximum likelihood estimator of parameter $p$ :

$$
\begin{aligned}
\hat{p}= & \sum_{i=1}^{c-1} i \cdot n(i+1) /\left[\sum_{i=1}^{c-1} i \cdot n(i+1)\right] \\
& +\left[\left(\sum_{i=1}^{c} n_{i}\right)-n_{c}\right]
\end{aligned}
$$

where $c$ is the number of seed density categories, $n_{i}$ is the number of observations in each category $i$. The expected and observed frequencies were not significantly different (chi-square goodness of fit, $\chi^{2}=3.6673, \mathrm{df}=5, P=$ 0.5982 ), indicating that the geometric distribution adequately modeled the empirical data (Fig. 3A). This 
probability density was randomly sampled to obtain the number of seeds in each defecation. The dispersal distance was selected by randomly sampling from the log-spline-smoothed distribution of dispersal distances for in-transit sites (Fig. 2A). Isotropy (radial symmetry around a source tree) was assumed, and a compass bearing was randomly selected from a uniform distribution $\left(0^{\circ}\right.$ to $\left.360^{\circ}\right)$. This process was repeated until all seeds to be dispersed in-transit from an individual tree had been dispersed.

Seeds dispersed to single-use sleeping sites.-Based on the observed frequency of sleeping site reuse, it was estimated that $33 \%$ of the seeds dispersed to sleeping sites would be dispersed to single-use sleeping sites. Seeds were dispersed to single-use sleeping sites by simulating individual defecations iteratively. Unlike intransit sites, single-use sleeping sites could receive more than a single defecation. To describe the distribution of seed densities at sleeping sites, a one-parameter geometric distribution was fit to the empirical distribution of these data (Fig. 3B) using the maximum likelihood parameter estimator (Eq. 1). The expected and observed frequencies were not significantly different (chi-square goodness of fit, $\chi^{2}=12.8646$, $\mathrm{df}=8, P=0.1166$ ), indicating a good fit to the data (Fig. 3B). By randomly sampling from this density, the number of seeds per defecation was selected. The number of individual defecations required to disperse all single-use sleepingsite seeds from a source tree was then determined. These defecations were partitioned into particular single-use sleeping sites, with each having multiple defecations. Field observations of the total number of defecations at individual single-use sleeping sites indicated that this distribution did not differ from a normal distribution (4.8 \pm 1.1 defecations, mean $\pm \mathrm{sD}$; chi-square goodness of fit, $\chi^{2}=3.5424, \mathrm{df}=3, P=0.3153$ ). This normal distribution was randomly sampled, and the resulting vector of values (each representing the total number of defecations at each individual single-use sleeping site) was combined with the vector of the number of seeds per defecation to determine the number of single-use sleeping sites required to disperse all single-use sleeping site seeds from each tree.

Single-use sleeping sites were simulated in the forest using a procedure similar to that used for in-transit dispersal. The distance to the southwestern corner of each single-use sleeping site from the source tree was determined by randomly sampling from the log-splinesmoothed distribution of dispersal distances to sleeping sites (Fig. 2B). A compass bearing was chosen randomly from a uniform distribution from $0^{\circ}$ to $360^{\circ}$. Once all of the single-use sleeping sites had been located, the appropriate number of defecations was distributed within each one. The areas of single-use sleeping sites were measured in the field and a normal distribution fit to these data $\left(\right.$ mean $=20.58 \mathrm{~m}^{2}, \mathrm{SD}=15.73 \mathrm{~m}^{2}$; Kolmogorov-Smirnov $D=0.235639, N=10, P=$
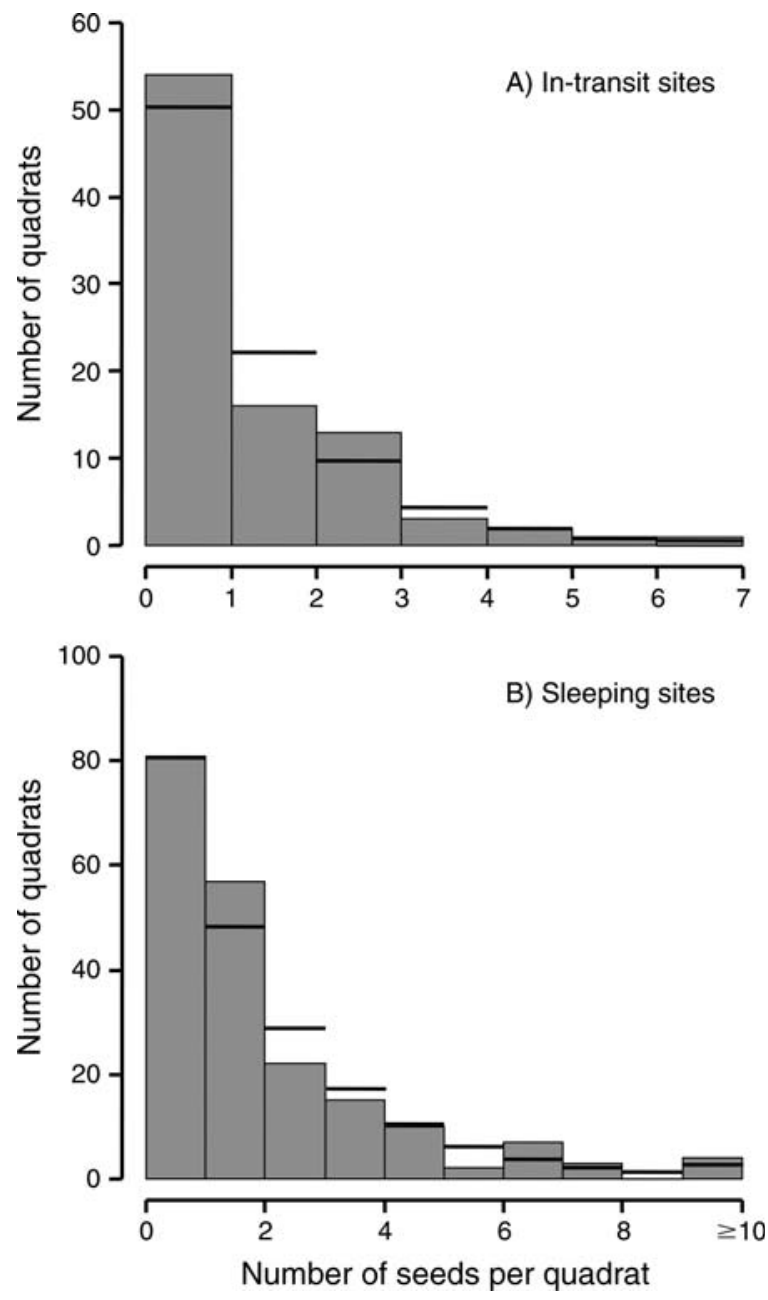

FIG. 3. Frequency distributions of seed densities at (A) intransit ( $N=90$ quadrats) and (B) sleeping ( $N=201$ quadrats) sites. Seed densities were measured in numbers of seeds per $0.25-\mathrm{m}^{2}$ quadrat. The observed seed densities are shown with gray bars, and densities modeled using a one-parameter geometric distribution are shown with line segments. In (B), the three largest seed densities $(23,12$, and 11 seeds/quadrat $)$ were placed in the final density category, $\geq 10$ seeds/quadrat.

0.1146). By randomly sampling from this distribution, an area for each single-use sleeping site simulated was selected. Seeds in defecations at each simulated sleeping site were randomly distributed within the area selected for that sleeping site.

Seeds dispersed to reused sleeping sites.-We estimated that $67 \%$ of the seeds dispersed to sleeping sites would be dispersed to reused sleeping sites. In contrast to singleuse sleeping sites, the locations and areas of the seven reused sleeping sites were fixed (Fig. 1). The probability that a particular reused sleeping site received seeds from a particular source tree depended on the distance between them. This process was simulated stochastically. First, all pairwise distances between a particular source tree and each of the reused sleeping sites were calculated. Second, the log-spline-smoothed distribution of sleeping 
site dispersal distances was evaluated at each distance calculated, resulting in a vector of the probabilities that each reused sleeping site is used, given the location of the source tree. Individual defecations were dispersed to the reused sleeping sites based on these probabilities. The number of seeds in each defecation was determined as described above for single-use sleeping sites.

Model output.-The output of the model was a seed shadow for each source tree represented by a matrix consisting of the number of seeds dispersed to particular locations. Each location represented actual geographic coordinates to the nearest centimeter, allowing the seed shadows of all 19 trees in the plot to be summed to obtain the seed-deposition pattern at the forest stand scale. The dispersal distances of seeds from each tree were calculated and summed onto a common axis, where 0.0 $\mathrm{m}$ represents the trunk of the tree, in order to estimate the dispersal curves for each individual tree and for seeds from all 19 source trees summed (the population-level seed-dispersal curve). The sample mean $(\bar{x})$, median, standard deviation (SD), skewness, and kurtosis of the distribution of seed dispersal distances were calculated, and $95 \%$ confidence intervals were estimated using bootstrapping (100 replicates). Unimodality of the distribution of dispersal distances was tested (Silverman 1981) based on a random sample of 1000 distances.

Probability distributions commonly used as dispersal kernels (exponential, normal, lognormal, Cauchy, Weibull, and 2Dt distributions; Appendix C; Clark et al. 1999, Nathan and Muller-Landau 2000, Greene et al. 2004) were fit to the simulated seed-dispersal curve for each of the 12 source trees with a crop size $>200$ seeds and to the simulated population-level seed-dispersal curve. To model the different seed dispersal processes in this system, a finite mixture distribution was also fit to the curves. Finite mixture distributions are weighted sums of two or more probability distributions and are useful for modeling data that may contain observations generated by different processes (Everitt and Hand 1981). Seeds were partitioned according to the different dispersal processes that produced them (non-dispersed seeds, seeds dispersed to sleeping sites, and seeds dispersed to in-transit sites). Because the distribution of distances for seeds at in-transit sites was bimodal (Fig. 2A), these seeds were further partitioned based on whether they were dispersed $<500 \mathrm{~m}$ or $\geq 500 \mathrm{~m}$. In exploratory analyses, different probability distributions were fit to each of these data partitions separately. The best-fitting distributions based on maximum likelihood were then used in a mixture distribution with the following distribution function:

$$
\begin{aligned}
F(x)= & s_{\mathrm{nd}} N(x ; \mu, \sigma)+s_{\mathrm{st}} W(x ; \alpha, \beta)+s_{\mathrm{its}} \log N(x ; \mu, \sigma) \\
& +s_{\mathrm{itl}} N(x ; \mu, \sigma)
\end{aligned}
$$

where $x$ is a seed dispersal distance; $\mathrm{s}_{\text {nd }}, \mathrm{s}_{\mathrm{st}}, \mathrm{s}_{\mathrm{its}}$, and $\mathrm{s}_{\mathrm{itl}}$ are the observed proportions of non-dispersed seeds and seeds dispersed to sleeping sites, short-distance $(<500 \mathrm{~m})$ in-transit sites, and long-distance $(\geq 500 \mathrm{~m})$ in-transit sites, respectively, which together sum to one; $N$ is the normal distribution; $W$ is the Weibull distribution; and $\log N$ is the $\operatorname{lognormal}$ distribution, with their respective parameters (Appendix C).

Parameters were estimated by finding the combination of parameter values that minimized the negative-loglikelihood function based on the Nelder-Mead algorithm (Nelder and Mead 1965). The Akaike Information Criterion (AIC) was used to compare the fits of the single-distribution and mixture-distribution dispersal kernels. AIC was estimated as $-2 L+2 p$, where $-L$ is the value of the negative log-likelihood function at which it is minimized by the model and parameters, and $p$ is the number of estimated parameters in the model (Hilborn and Mangel 1997). The parameter estimates for the single- and mixture-distribution dispersal kernels were then used to generate seed shadows based on the fecundity estimates for each source tree. We compared (1) the seed shadows based on these kernels to the simulated seed shadow and (2) the spatial variance in seed density resulting from the different seed shadows to evaluate how well these kernels reproduced the simulated seed shadow.

\section{Results}

The simulated spatial pattern of deposition of seeds from trees in the 38.7-ha study plot showed that, on average, $14.9 \%$ (95\% CI, 14.3-15.4\%) of a tree's seeds were dispersed outside of the plot. These seeds were primarily from dispersal to in-transit sites, although for trees near the plot boundary, seeds dispersed to singleuse sleeping sites also had a non-trivial probability of being dispersed outside of the plot. Because the locations of reused sleeping sites outside of the plot were unknown, the percentage of seeds dispersed outside of the study plot is likely an underestimate. The simulation accounts for all seed deposition within the study plot from source trees in the plot. Therefore, further examination will focus on the area within the study plot.

Simulated patterns of seed deposition within the study plot revealed substantial spatial variation in seed density (Fig. 4). The highest seed densities occurred underneath source trees. However, seed densities at reused sleeping sites were as high as or higher than at some source trees, depending on the size of the tree's seed crop. The seed density below trees with small seed crops was nearly indistinguishable from the background seed density, which is generated by dispersal to in-transit and sleeping sites.

The individual and population-level seed-dispersal curves were long-tailed and significantly multimodal $(P$ $<0.05$; Fig. 5). The long tail resulted from dispersal to in-transit sites, as seeds dispersed to these sites had longer dispersal distances than those to sleeping sites (Fig. 2) because spider monkeys moved faster during morning, relative to afternoon, foraging. The probabil- 


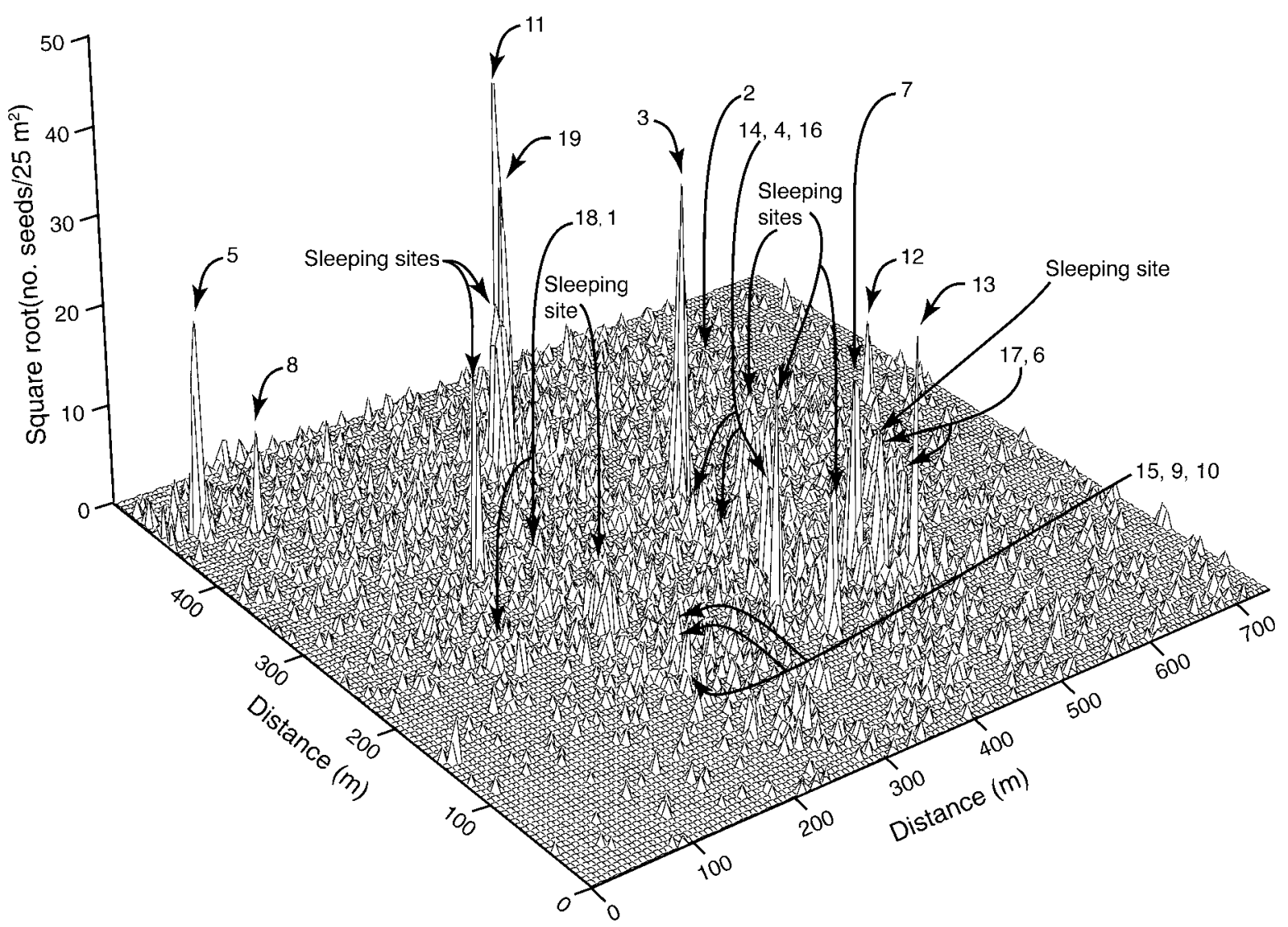

FIG. 4. The simulated seed-deposition pattern for $V$. calophylla seeds falling within the 38.7-ha study plot. Each cell corresponds to $25 \mathrm{~m}^{2}$. Numbered peaks correspond to parent trees, as in Appendix A and Fig. 1. Locations of peaks at sleeping sites correspond to the triangles in Fig. 1.

ity of seed dispersal was not a monotonically decreasing function of distance (Fig. 5). The multiple peaks resulted from the heterogeneity of dispersal generated by the three dominant processes determining seed deposition patterns in this system. Non-dispersed seeds created the mode at short distances $(<10 \mathrm{~m})$. The second mode, at 50-250 m, resulted not only from dispersal to sleeping sites, which had their modal dispersal distance in this region (Fig. 2B), but also from the added effect of dispersal to in-transit sites at these distances (Fig. 2A). The third, smaller mode at $800-1000 \mathrm{~m}$ resulted only from dispersal to in-transit sites. This mode reflects the locations of midday resting sites, which were often $>800$ $\mathrm{m}$ from the trees in which spider monkeys ingested seeds in the early morning.

The scale of seed dispersal is large for this $V$. calophylla population. On average, seeds moved $151 \mathrm{~m}$ from their source $(95 \% \mathrm{CI}=148-154 \mathrm{~m} ; \mathrm{SD}=241 \mathrm{~m}, 95 \%$ $\mathrm{CI}=236-246 \mathrm{~m}$; median $=34 \mathrm{~m}$, for all seeds), but there was substantial variation among individual trees (Appendix D). If only dispersed seeds are considered, then spider monkeys dispersed seeds an average of $245 \mathrm{~m}$ from source trees $(\mathrm{SD}=258$; median $=184 \mathrm{~m})$. Skewness and kurtosis of the distribution of dispersal distances were 2.5 and 6.0 , respectively.

The lognormal, Weibull, and 2Dt dispersal kernels fit poorly to the individual and population-level seeddispersal curves (Fig. 5A; Table 1; Appendix E). The poor fit resulted from the combined effects of the distribution's multimodality, its "fat," long tail, and its strong leptokurtosis near the source (Fig. 5A). Thus, none of these single-distribution kernels could adequately account for the mixture of dispersal processes generating the seed-dispersal curves. The mixture distribution fit the seed-dispersal curves better (Fig. 5B, Appendix F) because it separately modeled these different dispersal processes.

The fitted single- and mixture-distribution dispersal kernels varied in their abilities to reproduce the simulated seed shadow (Fig. 6). The lognormal, Weibull, and 2Dt dispersal kernels differed little in their resulting seed shadows (Fig. 6C-E). For these three kernels, short- to mid-range dispersal was overestimated, resulting in greater than observed densities near, but out from under, the crown of the source tree. The mixture distribution (Fig. 6B) more adequately reflected the spatial heterogeneity of the simulated seed shadow 


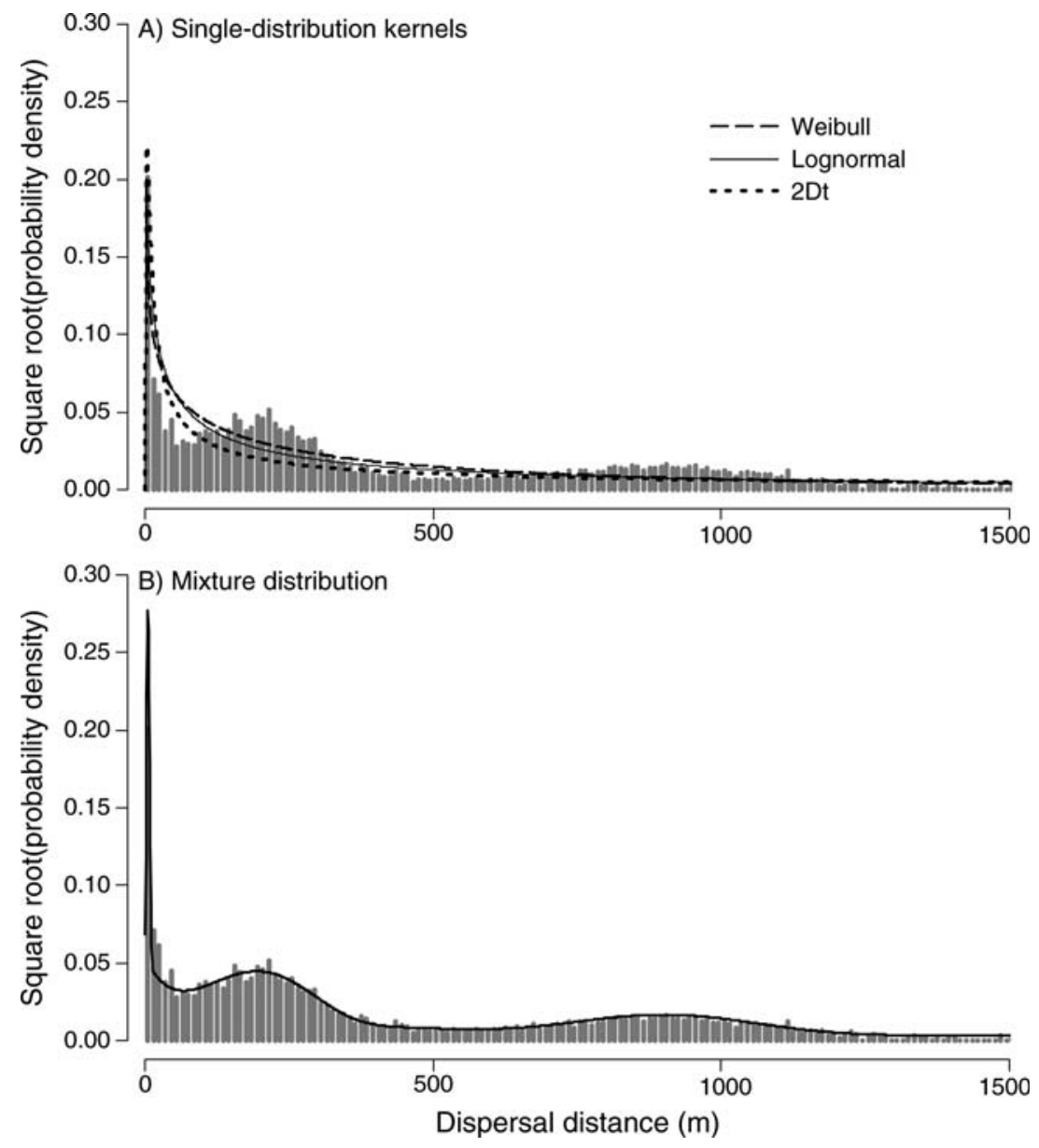

FIG. 5. (A) The three single-distribution seed dispersal kernels (Weibull, lognormal, and 2Dt) that best fit the simulated population-level seed-dispersal curve (gray histogram with numbers of seeds binned every $10 \mathrm{~m}$ ). Estimated parameters for each are in Table 1. (B) A mixture distribution fit to the simulated seed-dispersal curve (negative-log-likelihood score $=174256$ and Akaike's Information Criterion $=348$ 528). Estimated parameters for component distributions of the mixture model are: non-dispersed seeds, $N(\mu=5.05, \sigma=2.15)$; sleeping site seeds, $W(p=3.26, s=221.97)$; in-transit site seeds $(<500 \mathrm{~m}), \log N(\mu=4.50, \sigma=1.71)$; in-transit site seeds that were dispersed $\geq 500 \mathrm{~m}, N(\mu=901.50, \sigma=121.23)$. Probability density is plotted on a square-root transformed scale to aid visualization.

relative to the three dispersal kernels, but still overestimated densities near, but out from under, the source tree. However, because neither the single- nor the mixture-distribution kernels incorporated spatially explicit data on seed dispersal, none could account for the high seed densities at reused sleeping sites.

All dispersal kernels underestimated the spatial variance in seed density, as well as the degree of dispersal limitation (failure of seeds to reach any site). For the simulated seed shadow, the number of seeds in $25-\mathrm{m}^{2}$ quadrats in the plot ranged from 0 seeds $(81 \%$ of quadrats) to 1852 seeds (mean $=1.8$ seeds, $\sigma^{2}=770.9$ ). For the mixture distribution, these seed densities were more similar to the simulated seed shadow, but variance and dispersal limitation were still substantially underestimated (range: $0-657$ seeds $/ 25 \mathrm{~m}^{2} ; 50 \%$ of quadrats with 0 seeds; mean $=1.9$ seeds, $\sigma^{2}=319.3$ ). The seed shadow based on the 2Dt kernel reflected the observed dispersal limitation slightly more faithfully $\left(0-1050\right.$ seeds $/ 25 \mathrm{~m}^{2}$; $64 \%$ of quadrats with 0 seeds), but severely underestimated spatial variance in seed density (mean $=1.7$ seeds, $\left.\sigma^{2}=221.7\right)$. For the Weibull and lognormal kernels, seed density ranged from $0(53 \%$ and $57 \%$ of quadrats, respectively) to 862 and 1315 seeds $/ 25 \mathrm{~m}^{2}$, respectively (lognormal: mean $=1.7$ seeds, $\sigma^{2}=149.6$; Weibull: mean $=1.7$ seeds, $\sigma^{2}=202.3$ ).

\section{Discussion}

Our study demonstrated that models of seed dispersal by vertebrates should account for the behavior of dispersers in order to provide a realistic description of plants' seed shadows. For this $V$. calophylla population, the single-distribution kernels frequently used to model dispersal fit the seed-dispersal curve poorly, primarily because they could not account for the multimodality resulting from the different dispersal processes generated 
by spider monkeys' behaviors and movement patterns. Although a mixture distribution always fit the dispersal curve better, spatially explicit information on locations of spider monkey sleeping sites was still needed to reproduce both the seed shadow and spatial variance in seed densities accurately. Seed dispersal models are frequently used as the basis for plant demographic studies, particularly for predicting seedling population dynamics and spatial distributions. Such prediction requires an accurate representation of the initial seed distribution pattern. Compared to models that did not explicitly account for the disperser's behavior and movement patterns, our modeling approach improved prediction of the seed distribution pattern, which is critical for understanding how dispersal and postdispersal processes influence seedling recruitment.

Other studies have also found that mixture models perform better as dispersal kernels (Clark et al. 1998, Higgins and Richardson 1999, Bullock and Clarke 2000, Higgins et al. 2003, Jones et al. 2005). These studies largely focus on differences between rare, long-distance dispersal (the "tail" of the dispersal curve) and routine, local dispersal, which are often clearly described by different dispersal processes (Portnoy and Willson 1993, Clark et al. 2003, Higgins et al. 2003). Here, we demonstrate that even routine dispersal processes can produce multimodality in the dispersal curve because of patterns in the behavior and movement of animal dispersers.

\section{Implications for modeling seed dispersal}

The seed shadow of this $V$. calophylla population was spatially heterogeneous. Although most seeds fell undispersed below female $V$. calophylla trees, the fact that spider monkeys dispersed seeds in both clump- and scatter-dispersal patterns that had different modal dispersal distances also contributed substantially to heterogeneity. At sleeping sites, seed dispersal by spider monkeys was spatially aggregated, and seed densities there could be as high or higher than under source trees (Russo and Augspurger 2004). In contrast to the relatively shorter dispersal distances of seeds dispersed to sleeping sites, the longest dispersal distances resulted from seeds ingested during early morning foraging and defecated later the same day (at in-transit sites), after rapid, long-distance foraging movements, a pattern also seen in other primates (Stevenson 2000) and wideranging birds (Westcott et al. 2005). Although seeds were more scatter-dispersed at in-transit sites, the clumped dispersion of adults in this population (Russo and Augspurger 2004) increased the chances that even scatter-dispersed seeds fell close together.

Several studies have documented that the use of central places, such as leks, latrines, and favored foraging or sleeping sites, concentrates seed deposition and influences recruitment patterns (Fragoso 1997, Wenny 2000, Tewksbury and Nabhab 2001, Schupp et al. 2002, Russo and Augspurger 2004). By accounting
TABLE 1. Parameter estimates, negative log-likelihood score $(-L)$, and Akaike's Information Criterion (AIC) for fitting single-distribution dispersal kernels to the simulated population-level seed-dispersal curve.

\begin{tabular}{lllcc}
\hline \hline Distribution & Parameter 1 & Parameter 2 & $-L$ & AIC \\
\hline 2Dt & $p=0.21$ & $s=14.14$ & 181958 & 363920 \\
Cauchy & $\tau=14.58$ & $s=31.77$ & 206888 & 413780 \\
Exponential & $\lambda=0.01$ & $\mathrm{NA}$ & 191929 & 383860 \\
Lognormal & $\mu=3.56$ & $\sigma=1.96$ & 180254 & 360512 \\
Normal & $\mu=150.43$ & $\sigma=238.13$ & 219991 & 439986 \\
Weibull & $p=0.57$ & $s=92.75$ & 181105 & 362214 \\
& & & &
\end{tabular}

for both the spatial component of disperser movements and the locations and fecundities of source trees, our model demonstrated a clear link between the clumping of seeds in the seed shadow of a stand of trees and the multimodality of the corresponding seed-dispersal curve. Thus, models of seed dispersal cannot necessarily assume that areas of high seed rain only occur near parents (i.e., that probability of seed rain is a monotonically decreasing function of distance from the parent).

All single-distribution dispersal kernels substantially underestimated the spatial variance in seed density in this $V$. calophylla stand. The mixture distribution more faithfully reproduced this variance, but spatially explicit information on locations with high seed deposition was still required to estimate variance accurately. Underestimating variance in density among subpopulations will bias estimates of population growth at larger spatial scales when the population growth function is nonlinear (Chesson et al. 2005). It is thus essential for seed dispersal models to replicate the spatial variance in seed density in order to estimate seedling population dynamics correctly, particularly when the seed-to-seedling transition is density dependent, as in this system (Russo and Augspurger 2004; Chesson and Russo, unpublished manuscript). More generally, models that accurately predict seed distribution patterns are required for understanding the implications of seed dispersal for plant population dynamics and distribution, as well as for plant community structure. Our modeling approach substantially improved prediction of this $V$. calophylla population's seed distribution pattern relative to models that did not incorporate animal behavior.

Overall, the spatial scale of seed dispersal in this system was larger than that estimated for vertebratedispersed tree species using inverse modeling of data from seed traps in mapped tropical forest stands with similar disperser assemblages (Clark et al. 1999, Dalling et al. 2002). Several interacting factors may explain this discrepancy. The dispersal kernels used in inverse modeling may not adequately reflect the dispersal curves generated by animal dispersers, as suggested here and by the generally poorer fits for animal- vs. wind-dispersed species (Clark et al. 1999, Dalling et al. 2002). As a first step, more realistic mixture kernels for animals could be derived based on basic knowledge of a disperser's 


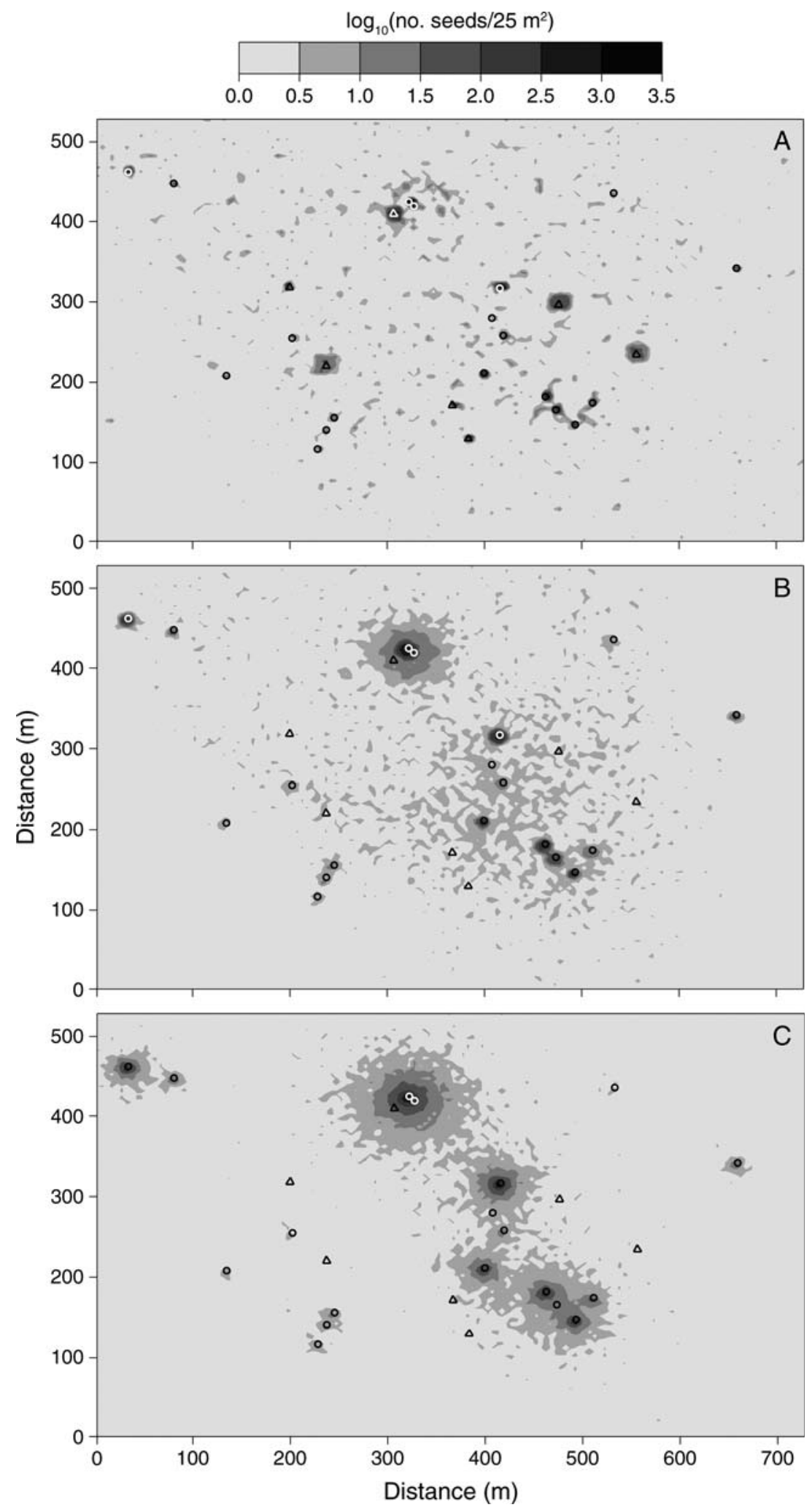

FIG. 6. Contour plots representing the seed shadow based on (A) the simulation model, (B) the mixture distribution, and (C-E) the three dispersal kernels that best fit the dispersal curves of individual source trees: (C) 2Dt, (D) lognormal, and (E) Weibull (Appendices E and F). Circles and triangles correspond, respectively, to source trees and reused sleeping sites. The gray scale represents the base-10 logarithmic transformation of seed density. 


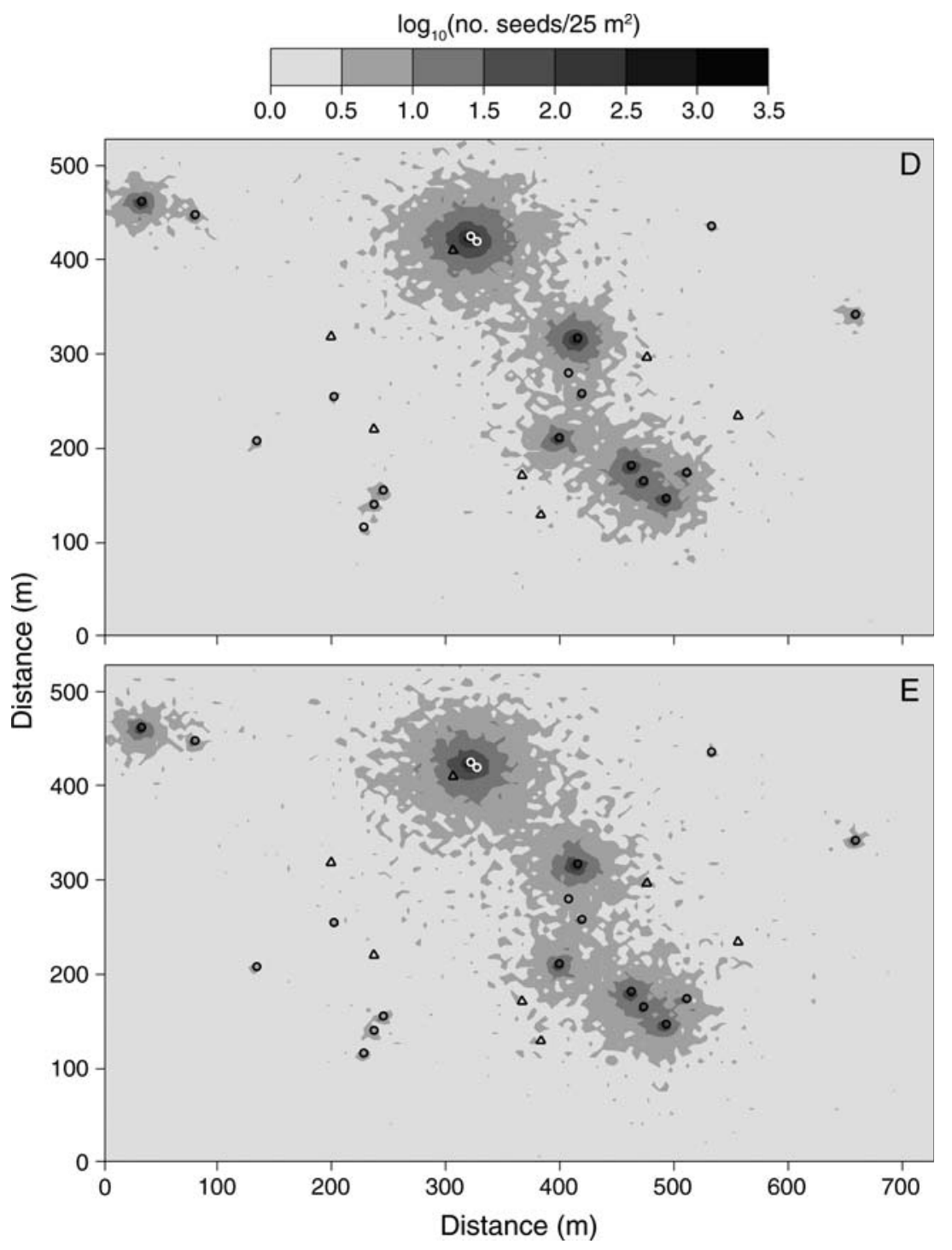

FIG. 6. Continued.

natural history and functional traits relevant to seed dispersal (e.g., body size, home range, and social system). Evidence also suggests that animal-generated dispersal curves are long-tailed (Portnoy and Willson 1993, Mack 1995, McConkey 2000, Westcott et al. 2005, Hardesty et al. 2006). Indeed, spider monkeys, as observed in other primates (Chapman and Russo 2006), routinely dispersed seeds $\gg 100 \mathrm{~m}$, a distance sometimes used to define long-distance dispersal among plants (Cain et al. 2000), but that may be too short to be considered rare, long-distance dispersal for some trees, as we and others have found (Clark et al. 2003, Jones et al. 2005, Hardesty et al. 2006). If dispersal scale exceeds plot size, then seed dispersal distances will be underestimated (Clark et al. 1999).

Furthermore, individual trees varied in terms of the goodness of fit of different dispersal kernels, due to differences in crop size, percentage of seed dispersal, and proximity to reused sleeping sites, highlighting the importance of allowing for individual variation in seed dispersal models. Studies of seed dispersal should therefore incorporate spatially explicit information on disperser behavior, be conducted at spatial scales large enough to capture routine long-distance dispersal, allow for individual variation, and use dispersal kernels, such as mixture distributions, that can account for the consequences of spatially aggregated seed dispersal.

\section{Comparisons with wind dispersal}

Mechanistic models of seed dispersal by animals are sometimes perceived as requiring more field data to parameterize relative to mechanistic models of dispersal by wind. Historically greater emphasis on mechanistic models of wind vs. animal dispersal has produced 
relatively more sophisticated wind dispersal models to date. Nonetheless, challenges to modeling dispersal persist for wind. For example, factors that likely influence spatial aggregation of wind-dispersed seeds still remain poorly described (Muller-Landau and Hardesty 2005). Some, such as quantifying entrainment of winds by the structure of natural plant canopies and ground cover, require fine-scale, long-term field data on wind speeds to parameterize models that account for spatiotemporal variation in wind speed, updrafts, and turbulence (Tackenberg 2003, Nathan and Katul 2005, Skarpaas et al. 2006).

Mechanistic models of dispersal by animals can, in principle, be as generalizable and predictive as winddispersal models. Challenges for mechanistic models of animal dispersal lie in developing approaches that are detailed enough to account for the behaviors and movements of the animals but sufficiently general so they may be applied to similar systems.

\section{Future directions}

Here we have presented an approach for developing a mechanistic model of seed dispersal that takes the plant's perspective but also captures the essential components of animal-disperser behavior affecting seed dispersal. Our approach to modeling vertebrate seed dispersal and predicting seed deposition patterns can be applied to any dispersal system by identifying which animals and their behaviors influence seed deposition patterns, paying particular attention to behaviors that may aggregate seeds. This information can then be used for particular dispersers to quantify the distributions of relevant parameters, such as dispersal distances, densities of dispersed seeds, and, if present, the locations and reuse frequencies of high seed-deposition areas. Future models might expand on the approach we have taken here by becoming increasingly mechanistic and predicting animal movements and behaviors on a finer scale directly from the traits of plants, fruits, and the animals themselves.

\section{ACKNOWLEDGMENTS}

Financial support was provided by a National Science Foundation Predoctoral Fellowship, Francis M. and Harlie M. Clark Research and Dissertation Travel Grants from the University of Illinois, and the Organization for Tropical Studies. The Instituto Nacionál de Recursos Naturales in Peru graciously allowed us to work in Manu National Park. George O. Batzli, Jeffrey D. Brawn, Charles Canham, Jason S. McLachlan, and Scott K. Robinson provided helpful comments on earlier versions of this manuscript. We are indebted to Julian Avery, Julian Huarancasi, Brian Lenz, Luis Alza Leon, Timothy Paine, and Jill Rowland for field assistance.

\section{Literature Cited}

Andresen, E. 1994. Frugivory and seed dispersal by spider monkeys (Ateles paniscus) and howler monkeys (Alouatta seniculus) and the fate of dispersed seeds at Manu National Park, Peru. Thesis. Duke University, Durham, North Carolina, USA.

Becker, R. A., and J. M. Chambers. 1984. S: an interactive environment for data analysis and graphics. Wadsworth, Belmont, California, USA.
Boinski, S., and P. A. Garber. 2000. On the move: how and why animals travel in groups. University of Chicago Press, Chicago, Illinois, USA.

Bullock, J. M., and R. T. Clarke. 2000. Long distance seed dispersal by wind: measuring and modeling the tail of the curve. Oecologia 124:506-521.

Cain, M. L., B. G. Milligan, and A. E. Strand. 2000. Longdistance seed dispersal in plant populations. American Journal of Botany 87:1217-1227.

Chapman, C. A., L. J. Chapman, and R. L. McLaughlin. 1989. Multiple central place foraging by spider monkeys: travel consequences of using many sleeping sites. Oecologia 79:506511.

Chapman, C. A., and S. E. Russo. 2006. Primate seed dispersal: linking behavioral ecology with forest community structure. Pages 510-525 in C. J. Campbell, A. F. Fuentes, K. C. MacKinnon, M. Panger, and S. Bearder, editors. Primates in perspective. Oxford University Press, Oxford, UK.

Chave, J., H. C. Muller-Landau, and S. A. Levin. 2002. Comparing classical community models: theoretical consequences for patterns of diversity. American Naturalist 159:123.

Chesson, P. L., M. J. Donahue, B. A. Melbourne, and A. L. W. Sears. 2005. Scale transition theory for understanding mechanisms in metacommunities. Pages 279-306 in M. Holyoak, M. A. Leibold, and R. D. Holt, editors. Metacommunities: spatial dynamics and ecological communities. The University of Chicago Press, Chicago, Illinois, UK.

Clark, J. S., C. Fastie, G. Hurtt, S. T. Jackson, C. Johnson, G. A. King, M. Lewis, J. Lynch, S. Pacala, C. Prentice, E. W. Schupp, T. Webb, III, and P. Wyckoff. 1998. Reid's paradox of rapid plant migration. BioScience 48:13-24.

Clark, J. S., M. Lewis, J. S. McLachlan, and J. HilleRisLambers. 2003. Estimating population spread: what can we forecast and how well? Ecology 84:1979-1988.

Clark, J. S., M. Silman, R. Kern, E. Macklin, and J. HilleRisLambers. 1999. Seed dispersal near and far: patterns across temperate and tropical forests. Ecology 80:1475-1494.

Dalling, J. W., H. C. Muller-Landau, S. J. Wright, and S. P. Hubbell. 2002. Role of dispersal in the recruitment limitation of Neotropical pioneer species. Journal of Ecology 90:714 727.

Dew, J. L. 2001. Synecology and seed dispersal in woolly monkeys (Lagothrix lagotricha poeppigii) and spider monkeys (Ateles belzebuth belzebuth) in Parque Nacional Yasuní, Ecuador. Dissertation. University of California, Davis, California, USA.

Everitt, B. S., and D. J. Hand. 1981. Finite mixture distributions. Chapman and Hall, London, UK.

Forget, P. M., and T. Milleron. 1991. Evidence for secondary seed dispersal by rodents in Panamá. Oecologia 87:596-599.

Fragoso, J. M. V. 1997. Tapir-generated seed shadows: scaledependent patchiness in the Amazon rain forest. Journal of Ecology 85:519-529.

Fragoso, J. M. V., K. M. Silvius, and J. A. Correa. 2003. Longdistance seed dispersal by tapirs increases seed survival and aggregates tropical trees. Ecology 84:1998-2006.

Greene, D. F., C. D. Canham, K. D. Coates, and P. T. Lepage. 2004. An evaluation of alternative dispersal functions for trees. Journal of Ecology 92:758-766.

Greene, D. F., and E. A. Johnson. 1989. A model of wind dispersal of winged or plumed seeds. Ecology 70:339-347.

Hardesty, B. D., S. P. Hubbell, and E. Bermingham. 2006. Genetic evidence of frequent long-distance recruitment in a vertebrate-dispersed tree. Ecology Letters 9:516-525.

Herrera, C. M. 2002. Seed dispersal by vertebrates. Pages 185 210 in C. M. Herrera and O. Pellmyr, editors. Plant-animal interactions: an evolutionary approach. Blackwell Science, Oxford, UK. 
Higgins, S. I., R. Nathan, and M. L. Cain. 2003. Are longdistance dispersal events in plants usually caused by nonstandard means of dispersal? Ecology 84:1945-1956.

Higgins, S. I., and D. M. Richardson. 1999. Predicting plant migration rates in a changing world: the role of long-distance dispersal. American Naturalist 153:464-475.

Hilborn, R., and M. Mangel. 1997. The ecological detective. Princeton University Press, Princeton, New Jersey, USA.

Holbrook, K. M., T. B. Smith, and B. D. Hardesty. 2002. Implications of long-distance movements of frugivorous rain forest hornbills. Ecography 25:745-749.

Holt, R. D., T. M. Knight, and M. Barfield. 2004. Allee effects, immigration, and the evolution of species niches. American Naturalist 163:253-262.

Howe, H. F. 1989. Scatter- and clump-dispersal and seedling demography: hypothesis and implications. Oecologia 79:417426.

Howe, H. F., and M. N. Miriti. 2004. When seed dispersal matters. BioScience 54:651-660.

Howe, H. F., E. W. Schupp, and L. C. Westley. 1985. Early consequences of seed dispersal for a Neotropical tree (Virola surinamensis). Ecology 66:781-791.

Hubbell, S. P. 2001. The unified neutral theory of biodiversity and biogeography. Princeton University Press, Princeton, New Jersey, USA.

Hurtt, G. C., and S. W. Pacala. 1995. The consequences of recruitment limitation: reconciling chance, history, and competitive differences between plants. Journal of Theoretical Biology 176:1-12.

Jones, F. A., J. Chen, G.-J. Weng, and S. P. Hubbell. 2005. A genetic evaluation of seed dispersal in the Neotropical tree Jacaranda copaia (Bignoniaceae). American Naturalist 166: 543-555.

Kooperberg, C., and C. J. Stone. 1991. A study of logspline density estimation. Computational Statistics and Data Analysis 12:327-347.

LaDeau, S. L., and J. S. Clark. 2001. Rising $\mathrm{CO}_{2}$ levels and the fecundity of forest trees. Science 292:95-98.

Levin, S. A. 1974. Dispersion and population interactions. American Naturalist 108:207-228.

Levine, J. M., and D. J. Murrell. 2003. The community-level consequences of seed dispersal patterns. Annual Review of Ecology, Evolution, and Systematics 34:549-574.

Mack, A. L. 1995. Distance and non-randomness of seed dispersal by the dwarf cassowary. Ecography 18:265-295.

McConkey, K. R. 2000. Primary seed shadow generated by gibbons in the rain forests of Barito Ulu, Central Borneo. American Journal of Primatology 52:13-29.

Milton, K. 1981. Food choice and digestive strategies of two sympatric primate species. American Naturalist 117:496-505.

Muller-Landau, H. C., and B. D. Hardesty. 2005. Seed dispersal of woody plants in tropical forests: concepts, examples, and future directions. Pages 267-309 in D. Burslem, M. Pinard, and S. Hartley, editors. Biotic interactions in the tropics. Cambridge University Press, Cambridge, UK.

Murray, K. G. 1988. Avian seed dispersal of three Neotropical gap-dependent plants. Ecological Monographs 58:271-298.

Nathan, R., and G. G. Katul. 2005. Foliage shedding in deciduous forests lifts up long-distance seed dispersal by wind. Proceedings of the National Academy of Sciences (USA) 102:8251-8256.

Nathan, R., and H. C. Muller-Landau. 2000. Spatial patterns of seed dispersal, their determinants and consequences for recruitment. Trends in Ecology and Evolution 15:278-285.

Nathan, R., U. N. Safriel, and I. Noy-Meir. 2001. Field validation and sensitivity analysis of a mechanistic model for tree seed dispersal by wind. Ecology 82:374-388.

Nathan, R., U. N. Safriel, I. Noy-Meir, and G. Schiller. 2000. Spatiotemporal variation in seed dispersal and recruitment near and far from Pinus halepensis trees. Ecology 81:21562169.

Nelder, J. A., and R. Mead. 1965. A simplex algorithm for function minimization. Computer Journal 7:308-313.

Norconk, M. A., and W. G. Kinzey. 1994. Challenge of neotropical frugivory: travel patterns of spider monkeys and bearded sakis. American Journal of Primatology 34:171-183.

Peres, C. A. 2000. Effect of subsistence hunting on vertebrate community structure in Amazonian forests. Conservation Biology 14:240-253.

Portnoy, S., and M. F. Willson. 1993. Seed dispersal curves: behavior of the tail of the distribution. Evolutionary Ecology 7:24-44.

Renne, I. J., W. C. Barrow, L. A. J. Randall, and W. C. Bridges. 2002. Generalized avian dispersal syndrome contributes to Chinese tallow tree (Sapium sebiferum, Euphorbiaceae) invasiveness. Diversity and Distributions 8:285-295.

Ribbens, E., J. A. Silander, and S. W. Pacala. 1994. Seedling recruitment in forests: calibrating models to predict patterns of tree seedling dispersion. Ecology 75:1794-1806.

Ripley, B. D. 2003. Statistical analysis of spatial point patterns. Oxford University Press, Oxford, UK.

Rodrigues, W. A. 1980. Revisao taxonomica das especies de Virola Aublet (Myristicaceae) do Brasil. Acta Amazonica 10: $1-127$.

Russo, S. E. 2003. Responses of dispersal agents to tree and fruit traits in Virola calophylla (Myristicaceae): implications for selection. Oecologia 136:80-87.

Russo, S. E. 2005. Linking seed fate to dispersal patterns: identifying factors affecting predation and scatter-hoarding of seeds of Virola calophylla in Peru. Journal of Tropical Ecology 21:243-253.

Russo, S. E., and C. K. Augspurger. 2004. Aggregated seed dispersal by spider monkeys limits recruitment to clumped patterns in Virola calophylla. Ecology Letters 7:1058-1067.

Russo, S. E., C. J. Campbell, J. L. Dew, P. R. Stevenson, and S. A. Suarez. 2005. A multi-forest comparison of dietary preferences and seed dispersal by Ateles spp. International Journal of Primatology 26:1017-1037.

Schupp, E. W., T. Milleron, and S. E. Russo. 2002. Dissemination limitation and the origin and maintenance of species-rich tropical forests. Pages 19-34 in D. J. Levey, W. R. Silva, and M. Galetti, editors. Seed dispersal and frugivory: ecology, evolution, and conservation. CABI Publishing, New York, New York, USA.

Silverman, B. W. 1981. Using kernel density estimates to investigate multimodality. Journal of the Royal Statistical Society B 43:97-99.

Skarpaas, O., R. Auhl, and K. Shea. 2006. Environmental variability and the initiation of dispersal: turbulence strongly influences seed release. Proceedings of the Royal Society B 273:751-756.

Slatkin, M. 1985. Gene flow in natural populations. Annual Review of Ecology and Systematics 16:393-430.

Sokal, R. R., and F. J. Rohlf. 1995. Biometry. W. H. Freeman, New York, New York, USA.

Stevenson, P. R. 2000. Seed dispersal by woolly monkeys (Lagothrix lagothricha) at Tinigua National Park, Colombia: dispersal distance, germination rates, and dispersal quantity. American Journal of Primatology 50:275-289.

Symington, M. M. 1987. Demography, ranging patterns, and activity budgets of black spider monkeys (Ateles paniscus chamek) in Manú National Park, Perú. American Journal of Primatology 15:45-67.

Tackenberg, O. 2003. Modeling long-distance dispersal of plant diaspores by wind. Ecological Monographs 73:173-189.

Terborgh, J. 1983. Five new world primates. Princeton University Press, Princeton, New Jersey, USA.

Tewksbury, J. J., and G. P. Nabhab. 2001. Directed deterrence by capsaicin in chilies. Nature 412:403-404. 
Wehncke, E. V., S. P. Hubbell, R. B. Foster, and J. W. Dalling. 2003. Seed dispersal patterns produced by white-faced monkeys: implications for the dispersal limitation of neotropical tree species. Journal of Ecology 91:677-685.

Wenny, D. G. 2000. Seed dispersal, seed predation, and seedling recruitment of a Neotropical montane tree. Ecological Monographs 70:331-351.

Westcott, D. A., J. Bentrupperbäumer, M. G. Bradford, and A. McKeown. 2005. Incorporating patterns of disperser behav- iour into models of seed dispersal and its effects on estimated dispersal curves. Oecologia 146:57-67.

Westcott, D. A., and D. L. Graham. 2000. Patterns of movement and seed dispersal of a tropical frugivore. Oecologia 122:249-257.

Wright, S. J., H. Zeballos, I. Dominguez, M. M. Gallardo, M. C. Moreno, and R. Ibanez. 2000. Poachers alter mammal abundance, seed dispersal, and seed predation in a Neotropical forest. Conservation Biology 14:227-239.

\section{APPENDIX A}

Crop size and seed dispersal for 19 source tress of Virola calophylla that produced fruit in 2001 in the study plot (Ecological Archives E087-191-A1).

\section{APPENDIX B}

Flow diagram of the seed dispersal simulation model indicating the four main subroutines (Ecological Archives E087-191-A2).

\section{APPENDIX C}

Functional forms and parameters of dispersal kernels (Ecological Archives E087-191-A3).

\section{APPENDIX D}

Summary statistics for the seed-dispersal curves generated for each source tree in the simulation model (Ecological Archives E087-191-A4).

\section{APPENDIX E}

Summary of parameter estimates, negative log-likelihood score, and Akaike's Information Criterion (AIC) for dispersal kernels fit to the simulated seed-dispersal curve for each source tree (Ecological Archives E087-191-A5).

\section{APPENDIX F}

Summary of parameter estimates, negative log-likelihood score and Akaike's Information Criterion (AIC) for the mixture distribution fit to the simulated seed-dispersal curve for each source tree (Ecological Archives E087-191-A6). 


\section{Ecological Archives E087-191-A1}

Sabrina E. Russo, Stephen Portnoy, and Carol K. Augspurger. 2006. Incorporating animal behavior into seed dispersal models: implications for seed shadows. Ecology 87: 3,160-3,174.

Appendix A. Crop size and seed dispersal for 19 source trees of Virola calophylla that produced fruit in 2001 in the study plot.

\begin{tabular}{|c|c|c|c|}
\hline Source tree & Diameter $(\mathrm{cm})$ & $\begin{array}{c}\text { Crop size (no. } \\
\text { seeds) }\end{array}$ & $\begin{array}{c}\text { Percentage of } \\
\text { seeds dispersed }\end{array}$ \\
\hline $1^{\mathrm{E}}$ & 36 & 60 & 29.4 \\
\hline $2^{\mathrm{E}}$ & 32 & 50 & 32.2 \\
\hline 3 & 34 & 4710 & 43.8 \\
\hline 4 & 26 & 201 & 48.9 \\
\hline $5^{\mathrm{E}}$ & 33 & 2000 & 50.7 \\
\hline $6^{\mathrm{E}}$ & 35 & 382 & 54.3 \\
\hline 7 & 35 & 2396 & 58.5 \\
\hline 8 & 25 & 284 & 63.3 \\
\hline 9 & 30 & 125 & 63.6 \\
\hline $10^{\mathrm{E}}$ & 28 & 100 & 66.4 \\
\hline 11 & 44 & 11963 & 66.5 \\
\hline 12 & 29 & 352 & 68.4 \\
\hline 13 & 33 & 2179 & 70.5 \\
\hline $14^{\mathrm{E}}$ & 39 & 26 & 71.3 \\
\hline $15^{\mathrm{E}}$ & 32 & 194 & 73.3 \\
\hline 16 & 23 & 2144 & 73.6 \\
\hline 17 & 39 & 1832 & 76.5 \\
\hline 18 & 38 & 78 & 77.8 \\
\hline 19 & 25 & 2278 & 92.5 \\
\hline
\end{tabular}

Notes: The superscript "E" indicates trees for which crop sizes were visually estimated and the percent of crop dispersed was assigned by randomly selecting it from the distribution of percent seed dispersal, as described in the text. Estimates for all other trees were from fruit traps underneath their crowns. Total seed production within the study plot was $810 \mathrm{seeds} / \mathrm{ha}$. 


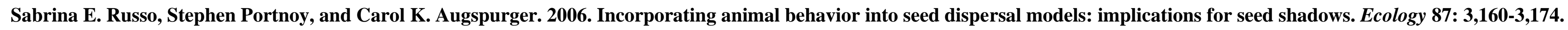
Appendix B. Flow diagram of the seed dispersal simulation model indicating the four main subroutines.

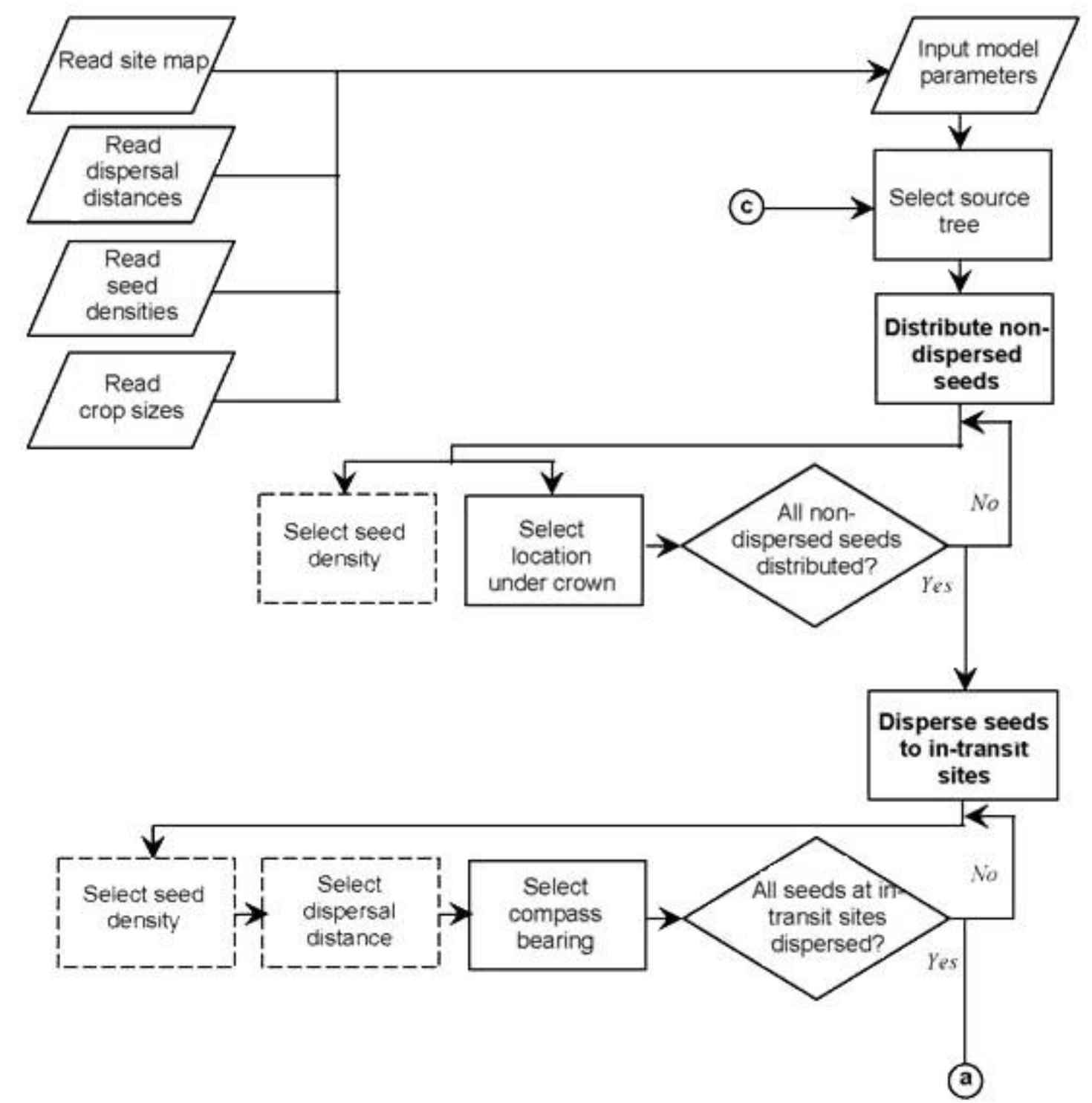




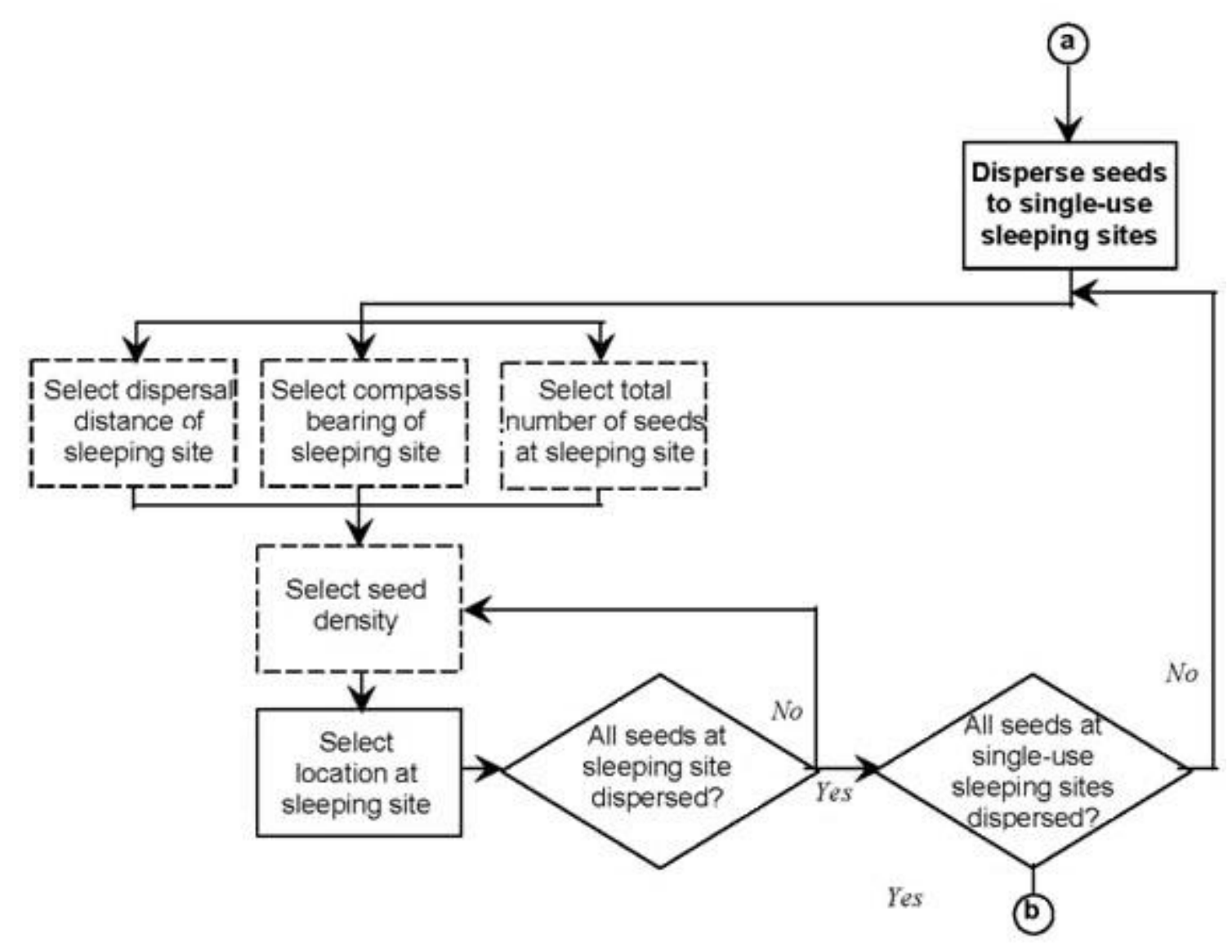




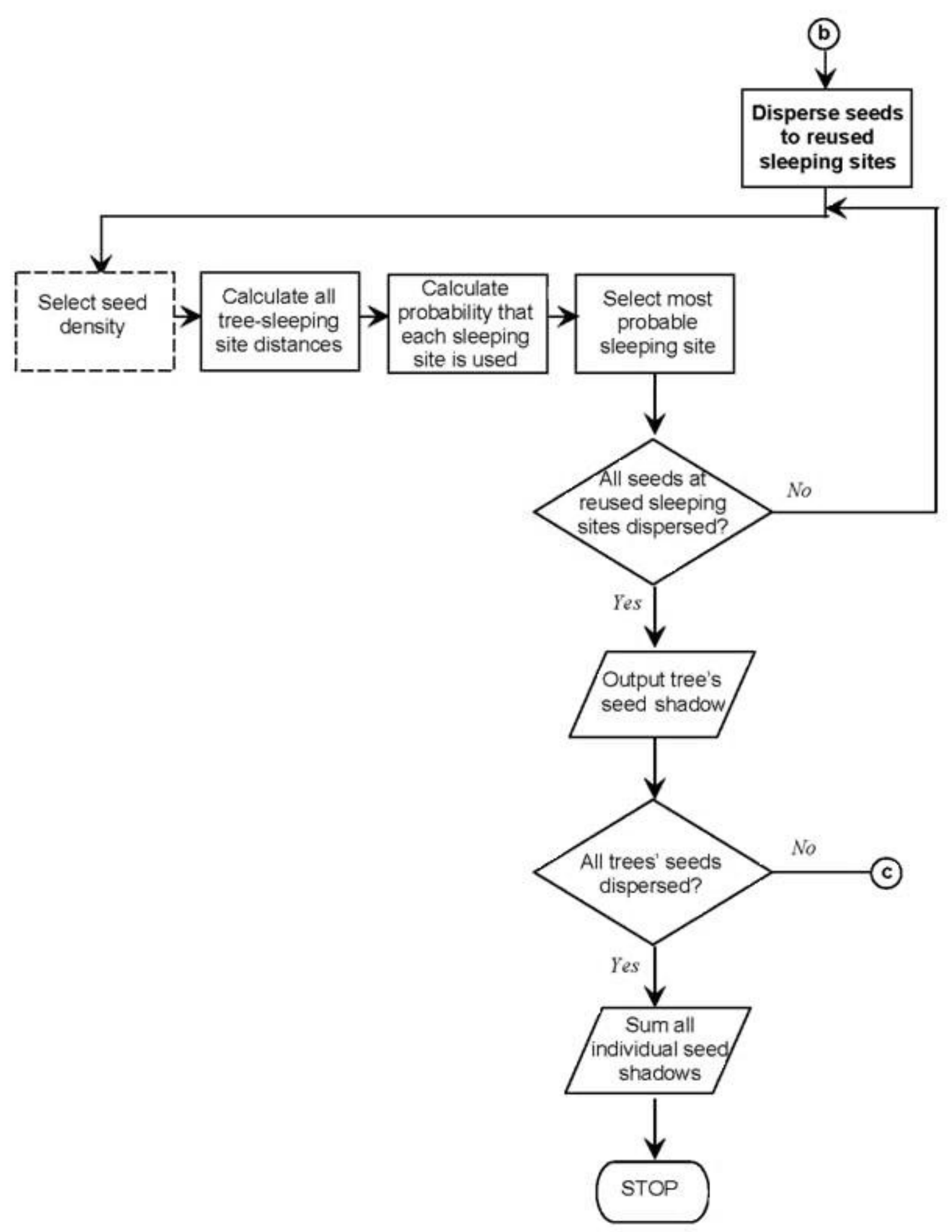

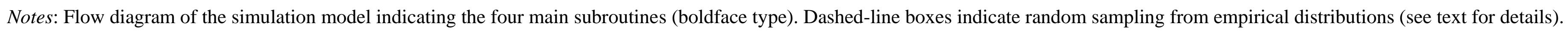




\section{Ecological Archives E087-191-A3}

Sabrina E. Russo, Stephen Portnoy, and Carol K. Augspurger. 2006. Incorporating animal behavior into seed dispersal models: implications for seed shadows. Ecology 87: 3,160-3,174.

Appendix C. Functional forms and parameters of dispersal kernels.

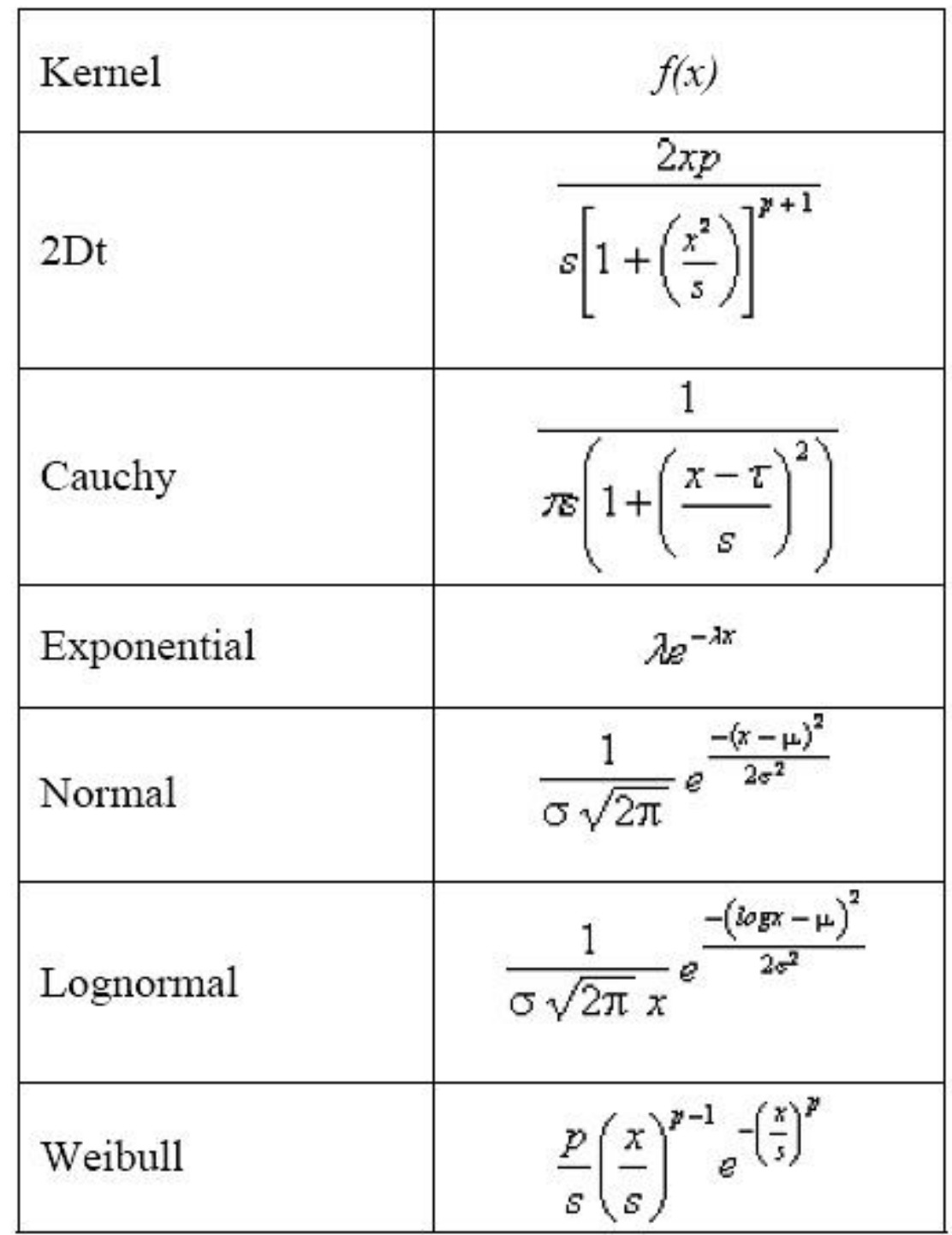

Notes: $x$ is the vector of seed dispersal distances, $p$ refers to shape parameters, $s$ refers to scale parameters, $\tau$ is the location parameter of the Cauchy distribution, $\lambda$ is the rate parameter of the exponential distribution, and $\mu$ and $\sigma$ refer to the mean and standard deviation (of the logarithm, in the case of the lognormal distribution). 


\section{Ecological ArchivesE087-191-A4}

Sabrina E. Russo, Stephen Portnoy, and Carol K. Augspurger. 2006. Incorporating animal behavior into seed dispersal models: implications for seed shadows. Ecology 87: 3,160-3,174.

Appendix D. Summary statistics for the seed-dispersal curves generated for each source tree in the simulation model.

\begin{tabular}{|c|c|c|c|}
\hline Source tree & Mean & Standard deviation & Median \\
\hline 1 & 119 & 206 & 8 \\
\hline 2 & 81 & 172 & 5 \\
\hline 3 & 106 & 200 & 8 \\
\hline 4 & 112 & 202 & 8 \\
\hline 5 & 142 & 233 & 7 \\
\hline 6 & 111 & 222 & 7 \\
\hline 7 & 143 & 243 & 43 \\
\hline 8 & 186 & 267 & 125 \\
\hline 9 & 130 & 143 & 150 \\
\hline 10 & 200 & 309 & 116 \\
\hline 11 & 150 & 245 & 22 \\
\hline 12 & 151 & 221 & 105 \\
\hline 13 & 175 & 259 & 108 \\
\hline 14 & 131 & 52 & 131 \\
\hline 15 & 181 & 231 & 125 \\
\hline 16 & 180 & 263 & 80 \\
\hline 17 & 174 & 233 & 108 \\
\hline 18 & 187 & 195 & 185 \\
\hline 19 & 216 & 291 & 127 \\
\hline
\end{tabular}

Notes: Summary statistics (m) for the seed-dispersal curves generated for each source tree in the simulation model. Statistics are calculated using both dispersed and non-dispersed seeds. Source tree numbers correspond to those in Appendix A. 


\section{Ecological Archives E087-191-A5}

Sabrina E. Russo, Stephen Portnoy, and Carol K. Augspurger. 2006. Incorporating animal behavior into seed dispersal models: implications for seed shadows. Ecology 87: 3,160-3,174.

Appendix E. Summary of parameter estimates, negative log-likelihood score and Akaike's Information Criterion (AIC) for dispersal kernels fit to the simulated seed dispersal curve for each source tree.

\begin{tabular}{|l|r|r|r|r|}
\hline Kernel & Parameter 1 & Parameter 2 & \multicolumn{1}{l|}{$-L$} & AIC \\
\hline & Source tree 3 \\
\hline Exponential & 0.01 & $\mathrm{NA}$ & 26985 & 53972 \\
\hline Gaussian & 106.51 & 200.05 & 31981 & 63966 \\
\hline Lognormal & $\mathbf{3 . 0 6}$ & $\mathbf{1 . 8 7}$ & $\mathbf{2 4 3 2 1}$ & $\mathbf{4 8 6 4 6}$ \\
\hline $2 \mathrm{Dt}$ & 0.26 & 12.37 & 23980 & 47964 \\
\hline Cauchy & 5.83 & 4.45 & 27175 & 54354 \\
\hline Weibull & 0.54 & 56.50 & 24785 & 49574 \\
\hline & Source tree 4 \\
\hline Exponential & 0.01 & $\mathrm{NA}$ & 1196 & 2394 \\
\hline Gaussian & 112.31 & 201.08 & 1405 & 2814 \\
\hline Lognormal & $\mathbf{3 . 1 3}$ & $\mathbf{1 . 8 6}$ & $\mathbf{1 0 8 0}$ & $\mathbf{2 1 6 4}$ \\
\hline 2Dt & 0.26 & 14.23 & 1061 & 2126 \\
\hline Cauchy & 5.71 & 4.51 & 1206 & 2416 \\
\hline Weibull & 0.54 & 60.10 & 1101 & 2206 \\
\hline & Source tree 5 \\
\hline Exponential & 0.01 & $\mathrm{NA}$ & 12226 & 24454 \\
\hline Gaussian & 141.51 & 233.20 & 14113 & 28230 \\
\hline Lognormal & $\mathbf{3 . 2 6}$ & $\mathbf{2 . 0 9}$ & $\mathbf{1 1 1 3 4}$ & $\mathbf{2 2 2 7 2}$ \\
\hline 2Dt & 0.21 & 7.87 & 11096 & 22196 \\
\hline Cauchy & 5.03 & 7.07 & 12931 & 25866 \\
\hline Weibull & 0.52 & 75.35 & 11236 & 22476 \\
\hline \hline & Source tree 6 \\
\hline Exponential & 0.01 & $\mathrm{NA}$ & 2204 & 4410 \\
\hline Gaussian & 110.85 & 221.55 & 2632 & 5268 \\
\hline Lognormal & $\mathbf{3 . 0 1}$ & $\mathbf{1 . 9 9}$ & $\mathbf{1 9 7 4}$ & $\mathbf{3 9 5 2}$ \\
\hline 2Dt & 0.22 & 5.72 & 1967 & 3938 \\
\hline Cauchy & 4.96 & 8.82 & 2288 & 4580 \\
\hline Weibull & 0.52 & 55.97 & 2003 & 4010 \\
\hline
\end{tabular}




\begin{tabular}{|l|r|r|r|r|}
\hline \multicolumn{5}{|c|}{ Source tree 7 } \\
\hline Exponential & 0.01 & $\mathrm{NA}$ & 14525 & 29052 \\
\hline Gaussian & 142.65 & 242.86 & 16843 & 33690 \\
\hline Lognormal & $\mathbf{3 . 4 8}$ & $\mathbf{1 . 9 2}$ & $\mathbf{1 3 5 2 0}$ & $\mathbf{2 7 0 4 4}$ \\
\hline 2Dt & 0.22 & 14.06 & 13549 & 27102 \\
\hline Cauchy & 15.86 & 35.19 & 15569 & 31142 \\
\hline Weibull & 0.56 & 85.07 & 13634 & 27272 \\
\hline & Source tree 8 \\
\hline Exponential & 0.01 & $\mathrm{NA}$ & 1780 & 3562 \\
\hline Gaussian & 185.64 & 267.02 & 2004 & 4012 \\
\hline Lognormal & 3.58 & 2.29 & 1667 & 3338 \\
\hline 2Dt & 0.16 & 3.59 & 1690 & 3384 \\
\hline Cauchy & 62.86 & 96.37 & 1945 & 3894 \\
\hline Weibull & $\mathbf{0 . 5 3}$ & $\mathbf{1 0 9 . 1 6}$ & $\mathbf{1 6 6 2}$ & $\mathbf{3 3 2 8}$ \\
\hline & Source tree 11 \\
\hline Exponential & 0.01 & $\mathrm{NA}$ & 72930 & 145862 \\
\hline Gaussian & 149.96 & 244.48 & 83945 & 167894 \\
\hline Lognormal & $\mathbf{3 . 5 5}$ & $\mathbf{1 . 9 0}$ & $\mathbf{6 8 0 6 5}$ & $\mathbf{1 3 6 1 3 4}$ \\
\hline 2Dt & 0.23 & 20.96 & 68360 & 136724 \\
\hline Cauchy & 11.29 & 19.52 & 77394 & 154792 \\
\hline Weibull & 0.57 & 90.47 & 68650 & 137304 \\
\hline & Source tree 12 \\
\hline Exponential & 0.01 & NA & 2208 & 4418 \\
\hline Gaussian & 150.88 & 220.28 & 2501 & 5006 \\
\hline Lognormal & 3.62 & 2.06 & 2112 & 4228 \\
\hline 2Dt & 0.18 & 7.38 & 2155 & 4314 \\
\hline Cauchy & 49.31 & 76.82 & 2417 & 4838 \\
\hline Weibull & $\mathbf{0 . 5 9}$ & $\mathbf{1 0 0 . 4 2}$ & $\mathbf{2 1 0 4}$ & $\mathbf{4 2 1 2}$ \\
\hline Exponential & 0.01 & $\mathrm{NA}$ & 13679 & 27360 \\
\hline Gaussian & 175.49 & 258.86 & 15471 & 30946 \\
\hline Lognormal & 3.66 & 2.19 & 13002 & 26008 \\
\hline 2Dt & 0.16 & 4.04 & 13311 & 26626 \\
\hline Cauchy & 67.99 & 81.90 & 14769 & 29542 \\
\hline Weibull & $\mathbf{0 . 5 6}$ & $\mathbf{1 1 0 . 7 5}$ & $\mathbf{1 2 9 2 6}$ & $\mathbf{2 5 8 5 6}$ \\
\hline & Source tree 16 \\
\hline
\end{tabular}




\begin{tabular}{|l|r|r|r|r|}
\hline Lognormal & 3.82 & 2.05 & 12949 & 25902 \\
\hline 2Dt & 0.17 & 7.93 & 13294 & 26592 \\
\hline Cauchy & 53.71 & 74.69 & 14538 & 29080 \\
\hline Weibull & $\mathbf{0 . 5 9}$ & $\mathbf{1 2 1 . 2 3}$ & $\mathbf{1 2 8 8 0}$ & $\mathbf{2 5 7 6 4}$ \\
\hline \multicolumn{5}{|r}{ Source tree 17 } \\
\hline Exponential & 0.01 & $\mathrm{NA}$ & 11543 & 23088 \\
\hline Gaussian & 174.05 & 232.49 & 12871 & 25746 \\
\hline Lognormal & 4.05 & 1.83 & 11379 & 22762 \\
\hline 2Dt & 0.20 & 28.51 & 11744 & 23492 \\
\hline Cauchy & 90.44 & 80.60 & 12395 & 24794 \\
\hline Weibull & $\mathbf{0 . 6 8}$ & $\mathbf{1 3 5 . 8 6}$ & $\mathbf{1 1 2 8 3}$ & $\mathbf{2 2 5 7 0}$ \\
\hline & Source tree 19 \\
\hline Exponential & 0.005 & $\mathrm{NA}$ & 14724 & 29450 \\
\hline Gaussian & 215.805 & 290.679 & 16380 & 32764 \\
\hline Lognormal & 4.207 & 1.821 & 14378 & 28760 \\
\hline 2Dt & 0.23 & 90.33 & 14782 & 29568 \\
\hline Cauchy & 64.569 & 90.097 & 15888 & 31780 \\
\hline Weibull & $\mathbf{0 . 6 5 6}$ & $\mathbf{1 6 0 . 7 0 3}$ & $\mathbf{1 4 3 2 4}$ & $\mathbf{2 8 6 5 2}$ \\
\hline & All seeds \\
\hline Exponential & 0.01 & $\mathrm{NA}$ & 191929 & 383860 \\
\hline Gaussian & 150.43 & 238.13 & 219991 & 439986 \\
\hline Lognormal & $\mathbf{3 . 5 6}$ & $\mathbf{1 . 9 6}$ & $\mathbf{1 8 0 2 5 4}$ & $\mathbf{3 6 0 5 1 2}$ \\
\hline 2Dt & 0.21 & 14.14 & 181958 & 363920 \\
\hline Cauchy & 14.58 & 31.77 & 206888 & 413780 \\
\hline Weibull & 0.57 & 92.75 & 181105 & 362214 \\
\hline & \multicolumn{5}{|c}{} \\
\hline
\end{tabular}

Notes: Summary of parameter estimates, negative log-likelihood score (-L), and Akaike's Information Criterion (AIC) for dispersal kernels fit to the simulated seed dispersal curve for each source tree with $>200$ seeds and for all seeds from all 19 source trees. Source tree numbers correspond to those in Appendix A. Dispersal kernels for all seeds are plotted in Fig. 5a. Boldface indicates the kernel with the lowest AIC; however, the 8-parameter mixture distribution always had a lower AIC than best-fitting single-distribution dispersal kernel (Appendix F). Parameters one and two (respectively) for each kernel are: exponential, $\lambda$; Gaussian, $\mu$ and $\sigma$;

Lognormal, $\mu$ and $\sigma ; 2 \mathrm{Dt}, \mathrm{p}$ and s; Cauchy, $\tau$ and s; Weibull, $\mathrm{p}$ and $\mathrm{s}$ (Appendix C). 


\section{Ecological Archives E087-191-A6}

Sabrina E. Russo, Stephen Portnoy, and Carol K. Augspurger. 2006. Incorporating animal behavior into seed dispersal models: implications for seed shadows. Ecology 87: 3,160-3,174.

Appendix F. Summary of parameter estimates, negative log-likelihood score, and Akaike's Information Criterion (AIC) for the mixture distribution fit to the simulated seed-dispersal curve for each source tree.

\begin{tabular}{|c|c|c|c|c|c|c|c|c|c|c|}
\hline \multirow[t]{3}{*}{$\begin{array}{l}\text { Source } \\
\text { tree }\end{array}$} & \multicolumn{2}{|c|}{$\begin{array}{l}\text { Non-dispersed } \\
\text { seeds }\end{array}$} & \multicolumn{2}{|c|}{$\begin{array}{l}\text { Sleeping site } \\
\text { seeds }\end{array}$} & \multirow{2}{*}{\multicolumn{2}{|c|}{$\frac{\mid \begin{array}{c}\text { In-transit } \\
\text { site seeds } \\
(<500 \mathrm{~m})\end{array}}{\underset{\begin{array}{c}\text { Lognorma } \\
1\end{array}}{ }}$}} & \multicolumn{2}{|c|}{$\begin{array}{c}\text { In-transit site } \\
\text { seeds }(\geq 500 \\
\text { m) }\end{array}$} & \multirow[t]{2}{*}{$-L$} & \multirow[t]{2}{*}{ AIC } \\
\hline & \multicolumn{2}{|c|}{ Gaussian } & \multicolumn{2}{|c|}{ Weibull } & & & \multicolumn{2}{|c|}{ Gaussian } & & \\
\hline & $\mu$ & $\sigma$ & shape & scale & $\mu$ & $\sigma$ & $\mu$ & $\sigma$ & & \\
\hline 3 & 5.01 & 1.99 & 1.35 & 158.40 & 5.24 & 0.21 & $\begin{array}{r}846.6 \\
5\end{array}$ & $\begin{array}{r}174.3 \\
6\end{array}$ & 21627 & 43270 \\
\hline 4 & 5.01 & 1.97 & 1.66 & 213.11 & 3.85 & 1.47 & $\begin{array}{r}725.5 \\
8\end{array}$ & $\begin{array}{r}292.5 \\
6\end{array}$ & 970 & 1956 \\
\hline 5 & 4.49 & 1.71 & 5.71 & 240.21 & 4.59 & 1.11 & $\begin{array}{r}896.0 \\
0\end{array}$ & $\begin{array}{r}166.2 \\
5\end{array}$ & 9724 & 19464 \\
\hline 6 & 5.00 & 2.00 & 1.41 & 159.66 & 4.60 & 0.99 & $\begin{array}{r}970.0 \\
5\end{array}$ & 78.78 & 1862 & 3740 \\
\hline 7 & 5.12 & 1.63 & 1.80 & 184.85 & 4.84 & 0.56 & $\begin{array}{r}904.9 \\
4\end{array}$ & $\begin{array}{r}157.7 \\
4\end{array}$ & 12049 & 24114 \\
\hline 8 & 3.17 & 1.25 & 5.92 & 223.40 & 4.96 & 0.98 & $\begin{array}{r}907.9 \\
9\end{array}$ & $\begin{array}{r}114.1 \\
6\end{array}$ & 1432 & 2880 \\
\hline 11 & 5.63 & 2.15 & 4.71 & 219.11 & 2.99 & 1.18 & $\begin{array}{r}745.5 \\
2\end{array}$ & $\begin{array}{r}268.0 \\
6\end{array}$ & 64283 & $\begin{array}{r}12858 \\
2\end{array}$ \\
\hline 12 & 3.60 & 1.27 & 1.03 & 153.60 & 5.21 & 0.20 & $\begin{array}{r}923.2 \\
6\end{array}$ & $\begin{array}{r}129.6 \\
5\end{array}$ & 1889 & 3794 \\
\hline 13 & 2.73 & 1.09 & 2.83 & 195.50 & 4.46 & 1.12 & $\begin{array}{r}882.8 \\
9\end{array}$ & $\begin{array}{r}135.7 \\
2\end{array}$ & 11787 & 23590 \\
\hline 16 & 3.33 & 1.23 & 1.30 & 113.59 & 5.38 & 0.22 & $\begin{array}{r}883.0 \\
8\end{array}$ & $\begin{array}{r}192.0 \\
6\end{array}$ & 11847 & 23710 \\
\hline 17 & 5.32 & 2.13 & 1.44 & 174.06 & 5.08 & 0.42 & $\begin{array}{r}886.9 \\
4\end{array}$ & $\begin{array}{r}172.4 \\
4\end{array}$ & 10637 & 21290 \\
\hline 19 & 3.39 & 1.22 & 2.82 & 243.34 & 3.15 & 0.33 & 850.0 & 196.5 & 13475 & 26966 \\
\hline
\end{tabular}




\begin{tabular}{|l|r|r|r|r|r|r|r|r|r|r|}
\hline & & & & & & & 0 & 1 & & \\
\hline & & & & & & & 901.5 & 121.2 & 17425 & 34852 \\
All seeds & 5.05 & 2.15 & 3.26 & 221.97 & 4.50 & 1.71 & 0 & 3 & 6 & 8 \\
\hline
\end{tabular}

Notes: Summary of parameter estimates, negative log-likelihood score $(-L)$, and Akaike's Information Criterion (AIC) for an 8-parameter mixture distribution fit to the simulated seed-dispersal curve for each source tree with $>200$ seeds and for all seeds from all 19 source trees. Source tree numbers correspond to those in Appendix A. The mixture distribution for all seeds is plotted in Fig. 5b. 